\title{
Compartmentalization of Photoreceptor Sensory Cilia
}

\author{
Cassandra L. Barnes, Himanshu Malhotra and Peter D. Calvert* \\ Department of Ophthalmology and Visual Sciences, Center for Vision Research, SUNY Upstate Medical University, Syracuse, \\ NY, United States
}

Functional compartmentalization of cells is a universal strategy for segregating processes that require specific components, undergo regulation by modulating concentrations of those components, or that would be detrimental to other processes. Primary cilia are hair-like organelles that project from the apical plasma membranes of epithelial cells where they serve as exclusive compartments for sensing physical and chemical signals in the environment. As such, molecules involved in signal transduction are enriched within cilia and regulating their ciliary concentrations allows adaptation to the environmental stimuli. The highly efficient organization of primary cilia has been co-opted by major sensory neurons, olfactory cells and the photoreceptor neurons that underlie vision. The mechanisms underlying compartmentalization of cilia are an area of intense current research. Recent findings have revealed similarities and differences in molecular mechanisms of ciliary protein enrichment and its regulation among primary cilia and sensory cilia. Here we discuss the physiological demands on photoreceptors that have driven their evolution into neurons that rely on a highly specialized cilium for signaling changes in light intensity. We explore what is known and what is not known about how that specialization appears to have driven unique mechanisms for photoreceptor protein and membrane compartmentalization. Hemant Khanna University of Massachusetts Medical School, United States Stephan C. F. Neuhauss, University of Zurich, Switzerland

*Correspondence:

Peter D. Calvert calvertp@upstate.edu

Specialty section:

This article was submitted to

Cell Adhesion and Migration,

a section of the journal

Frontiers in Cell and Developmental

Biology

Received: 01 December 2020

Accepted: 07 January 2021

Published: 04 February 2021

Citation:

Barnes CL, Malhotra H and Calvert PD (2021) Compartmentalization of

Photoreceptor Sensory Cilia. Front. Cell Dev. Biol. 9:636737. doi: 10.3389/fcell.2021.636737

Keywords: photoreceptors, transport, rhodopsin, peripheral membrane protein, soluble protein, primary cilia, trafficking, outer segment

\section{INTRODUCTION}

Vision in higher vertebrates evolved from ciliary epithelia. Light sensing in animals appears to have evolved from unicellular organisms like the alga Chlamydomonas where pigmented eyespots found in the eye organelles reside close to the flagella and support phototaxis by modulating flagellar beating (Gehring, 2004). There are two classes of photoreceptor cells in animals-ciliated and rhabdomeric. Ciliated photoreceptors, where light sensing is located within elaborate organelles having ciliary origins, are found mostly in deuterostomes. Rhabdomeric photoreceptors, where the light capturing organelles are microvilli, are mostly found in protostomes (Gehring, 2004; Lamb et al., 2007). Both ciliary and rhabdomeric photoreceptors originated from epithelial cells that possess cilia and microvilli (Lamb, 2013). The cilium disappeared in rhabdomeric photoreceptors, although the basal bodies were retained, leaving microvilli that are packed with rhabdomeric opsins. Vertebrate photoreceptors possess both ciliary and microvillar structures (Figure 1). The cilia contain rhodopsin and other components of the light transduction machinery localized to expanded ciliary membrane structures (lamellae and discs) in what is known as the outer segments (OS) while the microvilli evolved into support structures, known as calyceal processes, that extend along and in close juxtaposition with the OSs. 
A

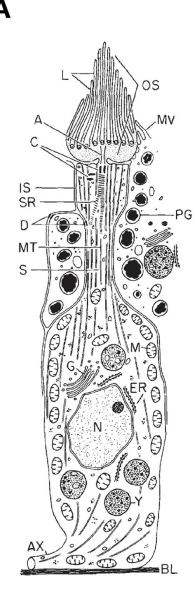

B

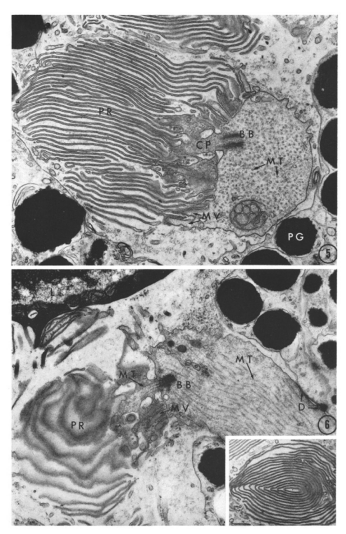

C



D

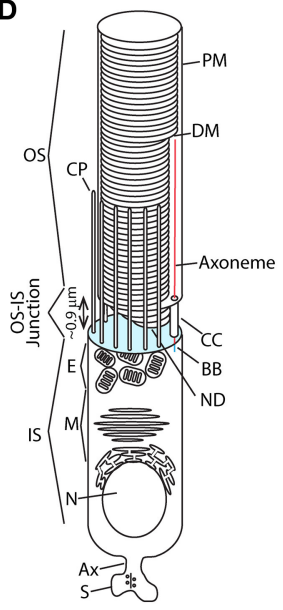

FIGURE 1 | Evolution of ciliary photoreceptors. (A) Schematic of an ascidian tadpole cerebral ganglion photoreceptor. Reproduced from Eakin and Kuda (1971). (B) Transmission electron micrographs of cerebral ganglion photoreceptors of Amaroucium constellatum larva. In the upper panel the section is perpendicular to the membrane lamellae. The lower panel is an image from a section parallel to the lamellar membranes. Reproduced from Barnes (1971). (C) Transmission electron micrograph of rod photoreceptors from mouse retina showing the CC, apical membrane region of the IS and nascent and enclosed discs of the OS. Note dense packing of nascent discs (arrowheads) and close juxtaposition of neighboring rods. Scale bar $1 \mu \mathrm{m}$. Reproduced from Ding et al. (2015). (D) Schematic of an amphibian rod. OS, outer segment; IS, inner segment; S, synaptic spherule; Ax, axon; N, nucleus; M, myoid; E, ellipsoid; CP, calycal process; ND, nascent disc; CC, connecting cilium; DM, mature disc membrane; PM, plasma membrane. Cyan: apical membrane. NDs are open to the extracellular milieu and contiguous with the CC and PM. DMs are enclosed within and separate from the OS PM and each other. Modified from Maza et al. (2019).

Photoreceptors bear a single cilium adapted for the highfidelity capture and sensation of photons. To meet this demanding function, they have evolved specialized ciliary membrane structures that support efficient photon capture. They support a constant flux of sodium and calcium ions across the ciliary plasma membrane, into the OS. Current flows through the connecting cilium (CC), into the cell body, known as the inner segment (IS), where an outward flux of potassium ions completes the circuit [reviewed in (Pugh and Lamb, 2000)]. The resulting membrane potential changes in a graded manner in response to changes in the light intensity falling on the

\footnotetext{
Abbreviations: AIPL1, Aryl hydrocarbon receptor interacting protein like 1; ARL13B, ADP-ribosylation factor-like protein 13B; Arl2, ADP-ribosylation factor-like protein 2; Arl3, ADP-ribosylation factor-like protein 3; Arr1, Arrestin 1; ATP, Adenosine triphosphate; BBS, Bardet-Biedl syndrome; CC, connecting cilium; COS, Cone outer segment; CNG1, Cyclic nucleotide-gated channel 1; DHA, Docosahexaenoic acid; PAGFP, Photoactivable green fluorescent protein; EGFP, Enhanced green fluorescent protein; ER, Endoplasmic reticulum; GARP, Glutamic acid rich protein; GC1, Guanylate cyclase-1; GDP, Guanosine diphosphate; GPCRs, G-protein coupled receptors; GRK1, G Protein-coupled receptor kinase 1; GTP, Guanosine triphosphate,; IC3, intracellular loop 3; IFT, Intraflagellar transport; INPP5E, Inositol polyphosphate-5-phosphatase E; IS, inner segment; Kif3A, kinesin family member 3A; OS, outer segment,; PC, phosphatidylcholine,; PDE6, rod photoreceptor phosphodiesterase 6; PE, Phosphatidylethanolamine; PI4P, Phosphatidylinositol 4-phosphate; PI(4,5)P2, Phosphatidylinositol (4,5)-bisphosphate; PLC, Phospholipase C; PrBP 8 , Prenyl-binding protein delta; PRCD, Progressive Rod-Cone Degeneration; Rho, Rhodopsin,; ROS, Rod outer segment; RIS, Rod inner segment; RTC, Rhodopsin transport carrier; Smo, Smoothened receptor; SSTR3, Somatostatin receptor 3; STX3, Syntaxin 3; T, G protein transducin; T $\alpha$, alpha subunit of transducin; T $\beta \gamma$, heterodimer of transducin beta and gamma subunits; TEM, Transmission electron microscope; TGN, Trans-Golgi network; TZ, Transition zone; Unc119, Uncoordinated 119.
}

photoreceptors-leading to graded modulation of the release of neurotransmitter at the synapse. In this way, the epithelial array of photoreceptors produces a receptor potential-encoded readout of the visual scene. $\mathrm{A} \mathrm{Na}^{+}, \mathrm{K}^{+}$antiporter burns ATP to maintain the ionic balance. Photoreceptors and the retina are, thus, amongst the most energetically demanding cells and tissues in the human body (Wong-Riley, 2010; Country, 2017). This metabolic activity leads to high levels of reactive oxygen species and rapid membrane and protein damage. To combat this damage photoreceptors turn over $\sim 10 \%$ of their OSs each day (Young, 1967; Young and Droz, 1968; Young and Bok, 1969; Besharse et al., 1977). Therefore, photoreceptors possess one of the most dynamic cilia found in nature. In this review, we examine what is known about the mechanisms by which photoreceptors generate and maintain the OS light signaling compartment and highlight critical knowledge gaps that impede complete understanding of photoreceptor function in health and disease.

\section{STRUCTURE AND FUNCTION OF CILIATED PHOTORECEPTORS}

A major challenge for photoreceptor light detection is capture and transduction of photons into electrical signals. Unlike chemical signals, which may dwell in the vicinity of sensory cilia for relatively long periods of time, enhancing probability of capture by relevant receptor proteins, photons are elusive, passing through sensory structures at the speed of light. Thus, photoreceptors evolved elaborate membrane systems packed with opsin molecules, the $G$ protein coupled light receptors, to 
increase the probability of photon capture (Figure 1). Ascidian larva, phylogenetically early chordates, possess photoreceptors where the ciliary membrane evolved into a comb like structure with tens of lamellar membranes (Figures 1A,B) (Barnes, 1971; Eakin and Kuda, 1971).

In higher vertebrates the number of lamellae is expanded to hundreds and tighter organization of the layers of opsin-containing membranes, typical of cone photoreceptors, is imposed (Anderson et al., 1978; Fetter and Corless, 1987). Following cones, rod photoreceptors evolved (Figure 1C), where the lamellae are replaced with thousands of internalized disc membranes that are discontiguous with each other and the OS plasma membrane (Nilsson, 1964; Nir and Pease, 1973; Tsukamoto, 1987; Nickell et al., 2007). Thus, whereas in cones opsins and other membrane proteins may diffuse between lamellae, in rods opsins are confined to the disc membrane into which they are packed for the lifetime of the disc. The lamellae and discs are oriented perpendicular to the path of photons entering the eye, such that photons run a gauntlet of opsin molecules that dramatically increases their probability of capture. The probability of photon capture in photoreceptor cilia is further enhanced by the structure of the photoreceptor ISs through what is known as the Stiles-Crawford effect of the first kind, the namesakes of which first quantified a differential sensitivity to light entering the eye at different angles (Stiles and Crawford, 1933). The photoreceptor ISs act as fiber optic-like waveguides, directing and concentrating light that enters the eye through the pupil into the OS. This waveguiding effect also reduces the capture of scattered photons, thus reducing "glare" and enhancing contrast (Enoch, 1980).

Photoreceptors have, therefore, evolved from ciliated epithelial cells to be super detectors of light with unparalleled efficiency. Indeed, owing to the high density of rhodopsin in each rod OS (Pugh and Lamb, 2000), the remarkable thermal stability of rhodopsin molecules that individually undergo spontaneous isomerization at the remarkably low rate of once in 1,000 years (Ashmore and Falk, 1977; Yau et al., 1979), the high quantum efficiency of rhodopsin $[\sim 0.65$, (Dartnall, 1972)], and the high gain of phototransduction (Pugh and Lamb, 2000), humans can reliably detect dim flashes that lead to single photon captures in 5 out of 500 rods (Hecht et al., 1942).

\section{CILIARY OUTER SEGMENT RENEWAL}

Unlike primary cilia, where GPCRs and other membrane proteins are delivered and removed from the cilium by secretory and endocytic processes, rhodopsin and other intrinsic membrane proteins are on a one-way ride-once they are packed into disc membranes they never return to the cell body. Instead, in all vertebrate species examined, $\sim 10 \%$ of the rod OS length is turned over daily (Young, 1967; Young and Droz, 1968; Young and Bok, 1969; Besharse et al., 1977) through shedding of hundreds of disc membranes at the distal tip of the OS (Figure 2) (Young, 1967; Besharse et al., 1977). Disc shedding is diurnally synchronized, occurring shortly after sunrise in diurnal species, or sunset in nocturnal species. Shed discs are



FIGURE 2 | Turnover of photoreceptor OSs. Stack of discs shed from a frog (Rana pipiens) rod OS, phagocytosed by a retinal pigment epithelial cell. ROS, rod OS; P, phagosome. Scale bar, $1 \mu \mathrm{m}$. Reproduced from Hollyfield et al. (1977).

ultimately phagocytosed by the retinal pigment epithelial (RPE) cells lying adjacent to the photoreceptor OSs at the back of the eye (Besharse et al., 1977). Shed discs are replaced by new disc membranes containing rhodopsin and other membrane proteins at the CC/transition zone (Burgoyne et al., 2015; Ding et al., 2015; Volland et al., 2015). Disc morphogenesis (see Figure 5) involves a lamellipodium-like, filamentous actin-mediated out pocketing of ciliary membrane (Spencer et al., 2019, 2020; CorralSerrano et al., 2020) that is initiated by a ciliary ectosome release mechanism (Nager et al., 2017; Phua et al., 2017) whose vesicular scission is suppressed by the tetraspanin protein, peripherin 2 (Salinas et al., 2017).

In lower vertebrates, this daily turnover represents an especially daunting challenge. Amphibian ciliary rod OSs have a diameter of up to $8 \mu \mathrm{m}$ and length up to $60 \mu \mathrm{m}$. The disc repeat frequency is $\sim 30 \mathrm{~nm}$. Approximately 200 discs, or $>20,000 \mu \mathrm{m}^{2}$ of membrane, turn over daily. This turnover includes 300 million rhodopsin molecules as well as $\sim 35$ million other molecules essential for light detection. Remarkably, $75 \%$ of this turnover occurs within $8 \mathrm{~h}$ after the onset of daylight (Besharse et al., 1977). At peak, components of disc membranes and phototransduction machinery are being fed to nascent discs at the base of the OS at the breakneck pace of $\sim 0.6 \mu \mathrm{m}^{2} \mathrm{~s}^{-1}$. In terms of membrane delivery alone, this rate is equivalent to generating seven primary cilia per minute. Mammalian photoreceptors have a diameter sevenfold smaller than amphibian photoreceptors and are $~ 50 \%$ shorter, thus, the daily demand for membrane and protein delivery to the OS is 100 -fold lower.

It is difficult to compare the photoreceptor rate of membrane turnover to the rate of primary ciliary membrane turnover. To our knowledge no direct experiment examining the turnover rate of primary cilium membrane has been published. Indeed, this sort of experiment would be difficult to achieve. Estimates can be made, however. Upon serum starvation, primary cilia of IMCD3 or hTERT-RPE1 cells occurs over the course of $\sim 12 \mathrm{~h}$, over which they extend to stable length of $\sim 5 \mu \mathrm{m}$. Thus, the effective membrane delivery rate for photoreceptors is 50 fold (mammalian) to 5,000-fold (amphibian) higher than that 



FIGURE 3 | Photoreceptors periciliary membrane systems. (A) Scanning electron micrographs of apical surfaces of frog (Rana pipiens) rods whose OSs where broken off, exposing the ISs. Note remnants of the CC (CC) recessed in pits at the periphery of the apical membranes (arrows). Membrane infoldings radiating from the connecting cilia are periciliary ridge complexes $(\mathrm{PRC})$. Inset $(2 \mathrm{C})$ is a transmission electron micrograph form a section cut perpendicular to the CC. Scale bars, 2A, $2 \mu \mathrm{m} ; 2 \mathrm{~B}, 0.5 \mu \mathrm{m} ; 2 \mathrm{C}, 0.5 \mu \mathrm{m}$. Reproduced from Peters et al. (1983). (B) Transmission electron micrograph through of a mouse rod where the plane of section bisected the $\mathrm{CC}(\mathrm{CC})$ and the basal body (BB). A deep ciliary pocket/periciliary membrane extends along one side of the CC (CC) and the nascent disc membranes (arrowhead). The opposite side of the CC abuts the neighboring photoreceptor. IS, IS; Mt, mitochondrion. Scale bare, $1 \mu \mathrm{m}$. Reproduced from Ding et al. (2015).

required for assembly of a primary cilium in a mammalian epithelial cell.

To meet the extraordinary demand for new discs and OS proteins, rod photoreceptors have evolved elaborate periciliary membrane systems that support docking and fusion of rhodopsin transport vesicles (RTCs) (Figure 3). Amphibian photoreceptors possess a periciliary ridge complex consisting of numerous deep folds in the apical membrane surface radiating from the axoneme and basal bodies (Peters et al., 1983) (Figure 3A). The periciliary membrane complex is less elaborate in mammalian photoreceptors, consisting of a single periciliary membrane structure extending along the full length of the CC (Figure 3B). The structure resembles the periciliary pocket associated with primary cilia that develop through the internal, ciliary vesicle mechanism (Benmerah, 2013). Indeed, the photoreceptor cilium develops via this mechanism (Pearring et al., 2013). The pocket associated with mammalian photoreceptors, however, does not completely encircle the CC, presumably due to the placement at the periphery of the cylindrical IS (Figure 3B).

\section{STRUCTURE OF THE PHOTORECEPTOR CONNECTING CILIUM}

The CC consists of basal bodies docked to the apical membrane, a $9+0$ microtubule axoneme with and a closely juxtaposed ciliary membrane (Figure 4). Extending between $0.5 \mu \mathrm{m}$ (amphibians) and $1.5 \mu \mathrm{m}$ (mammals) from the apical surface, the distal CC gives way to the elaborate OS system of disc (rods) or lamellar (cones) membranes and, in the case of rods, a plasma membrane physically separate from discs. The axoneme extends beyond this point, to between 60 and $100 \%$ of the OS length in rods (Brown et al., 1963; Kaplan et al., 1987; Sale et al., 1988; Eckmiller, 1996; Luby-Phelps et al., 2008) and 100\% of the cone OS length (Eckmiller, 1996). The photoreceptor axoneme can therefore reach $>30 \mu \mathrm{m}$ in length, although the distal half of the axoneme lose the B subfiber normally found in microtubules (Brown et al., 1963; Steinberg and Wood, 1975; Roof et al., 1991; Insinna et al., 2008).

The CC is thought to correspond to the transition zone (TZ) of primary cilia, although there are some differences. The TZ of all cilia contain a set of evolutionarily conserved proteins, including the Meckel syndrome complex and the nephronophthisis syndrome complex (Williams et al., 2011; Jensen et al., 2015; Li et al., 2016). For a detailed review of TZ proteins and associated diseases, see (Gonçalves and Pelletier, 2017). These proteins are thought to assemble the prototypical $\mathrm{Y}$ complexes that bridge the axoneme and ciliary membrane and to form diffusion barriers that regulate protein access to the ciliary compartment (Reiter et al., 2012; Gonçalves and Pelletier, 2017). Mutations in genes encoding these proteins leads to severe syndromic ciliopathies (Reiter and Leroux, 2017). However, mutations in several TZ proteins belonging to the RPGR complex, SPATA7, RPGRIP1, and RPGR, produce photoreceptor specific phenotypes, suggesting they are essential for photoreceptors but not for other cilia and flagella (Roepman et al., 2000; Hong et al., 2001; Murga-Zamalloa et al., 2010). This functional difference led to the hypothesis that the photoreceptor TZ contains a specialization required for assembly of the OS (Dharmat et al., 2018). Two CC regions were proposed, a proximal CC which is homologous to the $\mathrm{TZ}$ of primary cilia and the distal CC, which is a photoreceptor-specific extension of the ciliary TZ.

Recent advances in super-resolution fluorescence microscopy and high-resolution cryo-TEM tomography have revealed detailed structure of the TZ and localized protein composition at nanometer resolution (Figure 4) (Gilliam et al., 2012; Yang et al., 2015, 2018; Shi et al., 2017; Robichaux et al., 2019; Sun et al., 2019). An elegant STORM-based study showed detailed localization of 12 distal appendage-associated molecules and 4 additional proteins surrounding the distal appendages (Yang et al., 2018) and super-resolution STED imaging mapped the distribution of TZ complex proteins in primary cilia (Yang et al., 2015). Studies of the CC demonstrated structural details of basal bodies and the axoneme, showing microtubule triplets and doublets, respectively, along with distal appendages (Gilliam et al., 2012; Robichaux et al., 2019). Ninefold averaging of cryo-EM tomograms revealed $\mathrm{Y}$ link-like structures in the lumen of the CC (Figure 4A), a hallmark of the TZ, although the structures appeared to be formed from two independent structures rather than the single structure observed in standard TEM studies in primary cilia (Robichaux et al., 2019). Interestingly, the tomograms also revealed a structure resembling the terminal plate found in motile cilia 
A

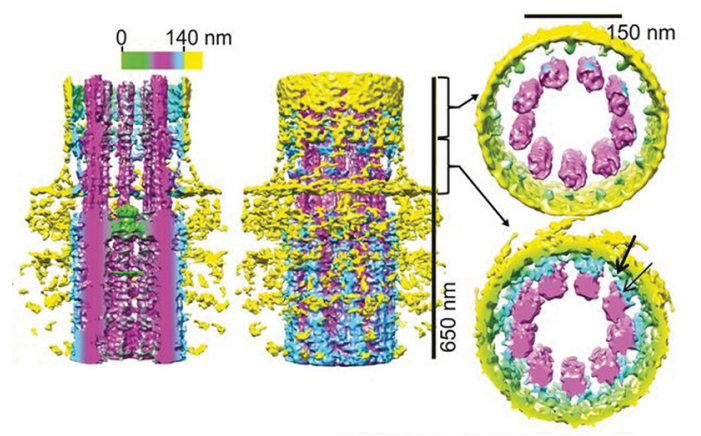

C

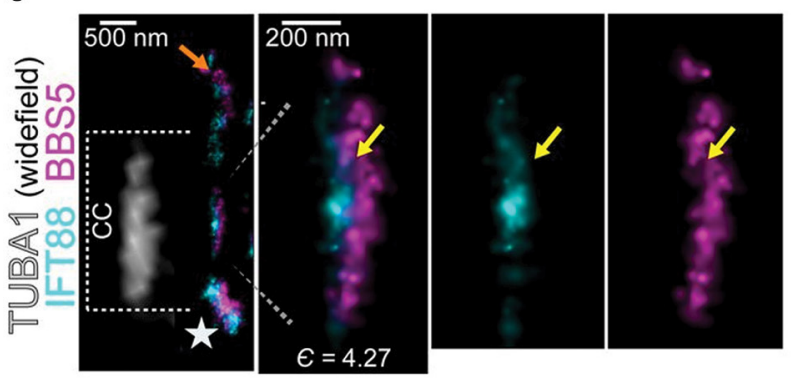

B

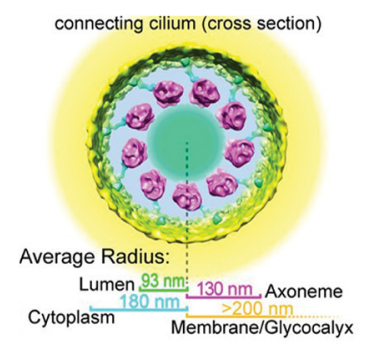

FIGURE 4 | Structure of the photoreceptor CC. (A) Surface representations of cryo-EM tomographs subject to 9-fold sub tomograph averaging. Left, section through the ciliary axis, color bar codes distance from center. Middle, entire map. Right upper, distal cross section of the transition zone. Right lower, proximal transition zone cross section shows Y-link-like structures (cyan) projecting between the axoneme (magenta) and the ciliary membrane (yellow). (B) Diagram showing the resolution of concentric layers of the CC determined by STORM microscopy, overlaid on cryo-EM tomographic map of ciliary cross section. (C) STORM localization maps a CC co-labeled with IFT88 and BBS5. Left panel shows tubulin in bright field to delineate the CC length. Expanded images show close juxtaposition of IFT88 (cyan) and BBS5 (magenta). Right two panels show individual channels. Yellow arrows are suggested to show co-localization. Modified from Robichaux et al. (2019).

(Figure 4A). Super-resolution microscopy of immunolabeled proteins revealed concentric layering of the CC (Figure 4B) (Robichaux et al., 2019). Overlapping localization of IFT88, IFT81, and BBS5 distribution across CC was also observed (Figure 4C), suggestive of IFT trains. Interestingly, CEP290, which is present at the base of the primary cilium, was present along the entire CC along with Y-links (Potter et al., 2020). These results have strengthened the notion that the entire length of the $\mathrm{CC}$ operates as the photoreceptor transition zone.

A feature common to all cilia is that, despite contiguous plasma and ciliary membranes, the ciliary compartment is physically distinct from the plasma membrane [reviewed in (Garcia et al., 2018)]. This separation is thought to be mediated, in part, by diffusion barriers. For membrane proteins, septin cytoskeletal components may operate as diffusion barriers, retaining ciliary membrane proteins and keeping plasma membrane proteins out. Knockdown of SEPT2 led to normally ciliary confined membrane proteins to exit the primary cilium (Hu et al., 2010). It is possible that two diffusion barriers for membrane proteins exist at the primary cilium base. Superresolution single molecule tracking revealed that BBSomemediated transport of agonist activated SSTR3 receptor out of primary cilia required crossing two diffusion barriers, one of which was more stringent (Ye et al., 2018). Super-resolution microscopy studies have shown that the transition zone may be a "waypoint" for proteins where entry or rejection decisions are made (Milenkovic et al., 2015; Shi et al., 2017), perhaps through a matrix/gel-like structure at the distal appendages (Yang et al., 2018). To date the membrane diffusion barrier at the $\mathrm{CC}$ has not been identified. Soluble proteins do not appear to be as restricted. Proteins up to $\sim 70 \mathrm{kDa}$ can pass through the ciliary transition zone of primary cilia and the photoreceptor CC without impediment (Calvert et al., 2010; Najafi et al., 2012; Breslow et al., 2013; Lin et al., 2013; Awata et al., 2014).

\section{INTRAFLAGELLAR TRANSPORT IN PHOTORECEPTORS}

Intraflagellar transport (IFT) is a motor driven process, first observed by Kozminski and Rosenbaum in Chlamydomonas sensory flagella (Kozminski et al., 1993; Rosenbaum and Witman, 2002), that is involved in assembly, maintenance, length control, and selective transport of cargo into and out of cilia and flagella (Sedmak and Wolfrum, 2011; Prevo et al., 2017). IFT is mediated by large complexes of proteins that form "IFT trains" which can move in either direction along the cilium. Two classes of IFT have been characterized; IFT-A moves in the retrograde direction, from cilium tip to base, utilizing dynein motors, whereas IFT-B moves in the anterograde direction via kinesin motors (Scholey, 2013; Lechtreck, 2015; Reilly and Benmerah, 2019; Webb et al., 2020). The IFT complex itself is a super-molecular structure that possesses both IFT-A and IFT-B components working together in ciliary protein import and export (Kobayashi et al., 
2020). The transport direction and specific cargo depend on switching mechanisms that determine which class of motors engage the axoneme through mechanisms that are not entirely understood (Jordan et al., 2018). Importantly, recent results show that anterograde transport occurs on the $\mathrm{B}$ microtubules and retrograde on the $\mathrm{A}$ microtubules of the microtubule doublets (Stepanek and Pigino, 2016), thus avoiding traffic jams. IFT malfunction results in syndromic or non-syndromic diseases (Bujakowska et al., 2015), that impact many organ systems, including but not limited to retina, brain, kidney, reproductive organs, and cause obesity [reviewed in Reiter and Leroux (2017)].

In photoreceptors, IFT is involved in the development and maintenance of photoreceptor OSs (Pazour et al., 2002) and is proposed to be involved in the trafficking of opsins and membranes destined for the OS discs or lamellae (Pearring et al., 2013; Wheway et al., 2014; Imanishi, 2019). IFT52, 57, 88, and 20 have been identified along the OS axoneme and within the IS of Xenopus photoreceptors (Luby-Phelps et al., 2008) and IFT88 and 81 in the CC of mouse photoreceptors (Robichaux et al., 2019) (Figure 4). Mutations in IFT proteins have been shown to cause mislocalization of rhodopsin and accumulation of membrane vesicles in the IS. For example, IFT20 is implicated in trafficking of rhodopsin from the Golgi to the base of the OS (Follit et al., 2006) and mutation in IFT122 in zebrafish appeared to delay opsin transport to the OS, causing progressive photoreceptor degeneration (Boubakri et al., 2016). IFT proteins have also been found to be associated with basal bodies prior to elaboration of the OS in developing retinal photoreceptors, suggesting IFT proteins may be playing a role in early photoreceptor ciliogenesis (Sedmak and Wolfrum, 2011). While many of these studies show mislocalization of rhodopsin and conclude that the mutations impact its trafficking, it is not clear that they represent direct, causal relationships. In addition to uncoupling of cargo from IFT, mistrafficking could result from improper ciliogenesis or perturbation in the homeostasis of the CC. Moreover, to date there is no direct evidence that opsins transport via IFT within the CC.

The dynamics of IFT proteins and co-transport of IFT cargos within cilia and flagella have been exhaustively explored in various model systems including mammalian cells, Chlamydomonas flagella and sensory neurons of C. elegans. These studies have led to detailed, quantitative descriptions of the frequency, kinetics and size of IFT trains and their cargoes (Pigino et al., 2009; Taschner et al., 2014, 2018; Stepanek and Pigino, 2016; Vannuccini et al., 2016; Jordan et al., 2018; Yang et al., 2019; Kiesel et al., 2020). In Chlamydomonas, it is estimated that, on average, $\sim 10-12$ IFT trains are present per flagellum (Vannuccini et al., 2016; Wingfield et al., 2017). There appear to be two sizes of trains, short trains averaging $\sim 250 \mathrm{~nm}$ and long trains of $\sim 650 \mathrm{~nm}$ (Pigino et al., 2009; Vannuccini et al., 2016). The rate off IFT transport in Chlamydomonas flagella on average is $\sim 2 \mu \mathrm{m} \mathrm{s}^{-1}$ anterograde and $\sim 3 \mu \mathrm{m} \mathrm{s}^{-1}$ retrograde (Wingfield et al., 2017). IFT rates in primary cilia have been estimated to be $\sim 0.6 \mu \mathrm{m} \mathrm{s}^{-1}$ anterograde and $\sim 0.3 \mu \mathrm{m} \mathrm{s}^{-1}$ retrograde (Follit et al., 2006; Ye et al., 2013; Broekhuis et al., 2014; Lee et al., 2018a). Such quantification allows estimates of the cargo carrying capacity and rate of cargo delivery by IFT. No direct high-resolution studies of IFT dynamics within photoreceptor connecting cilia have been achieved, however, representing a substantial knowledge gap.

There are several studies suggesting non-IFT trafficking of cargo may play a larger role than previously appreciated. In Chlamydomonas flagella IFT mediated trafficking of tubulin is predominant when flagella are extending, but diffusion of tubulin within the flagellum predominates during steady-state axonemal turnover (Craft et al., 2015). Soluble EGFP or PAGFP and concatemers of up to three of these proteins diffuse into Xenopus photoreceptor OS, showing that soluble proteins as large as $80 \mathrm{kDa}$ do not require active IFT transport (Calvert et al., 2010; Najafi et al., 2012). Similar results were found for soluble proteins in primary cilia (Breslow et al., 2013). Diffusion was also reported to be a major mode of transport for intrinsic membrane proteins in cilia (Ye et al., 2013; Milenkovic et al., 2015; Lee et al., 2018a).

\section{THE BBSome IN PHOTORECEPTORS}

Bardet-Biedl syndrome (BBS) is a ciliopathy resulting from mutations in multiple genes that lead to retinal degeneration, polydactyly, morbid obesity and kidney disfunction among other disorders (Hernandez-Hernandez and Jenkins, 2015; Nachury, 2018; Wingfield et al., 2018). Eight of these genes encode proteins that form the BBSome, a complex involved in protein trafficking and ciliogenesis, including photoreceptor morphogenesis (Hsu et al., 2017). The BBSome shares common structural elements with COPI, COPII, and clathrin coats, indicating a role in membrane and membrane protein transport. The BBSome has been shown to be involved in entry of intrinsic membrane proteins into cilia. For example, the GPCRs SSTR3 and MCHR1 failed to localize to primary cilia of hippocampal neurons from $\mathrm{BBS}^{-/-}$and BBS4${ }^{-/-}$mice (Berbari et al., 2008).

Recent studies suggest the BBSome plays a major role in removal of membrane and soluble proteins from cilia. Primary cilia from central neurons in mice where BBS2, BBS4, or BBS7 are knocked out resulted in accumulation of the dopamine 1 receptor (DP1) in cilia and agonist-induced transport of DP1 out of the cilia was reduced (Domire et al., 2011; Zhang et al., 2013). Primary cilia in mouse embryonic fibroblasts (MEFs) from $\mathrm{BBS}^{-/-}$and $\mathrm{BBS}^{-/-}$mice accumulate Patch 1 and Smo receptors in the absence of smoothened agonist, SAG (Zhang et al., 2011b, 2012). Smo accumulates in cilia of $\mathrm{BBS}^{-/-}$ RPE1 cells in the absence of SAG ligand while GPR161 was retained in cilia after ligand treatment (Nozaki et al., 2018). These results show that BBSome transport is required for removal of these receptors from primary cilia. BBSome-dependent removal of activated SSTR3 and Smo from primary cilium of IMCD3 cells requires the adapter proteins $\beta$-arrestin 2 , which binds to activated, phosphorylated GPCRs, and Tulp3 (tubby-like protein 3 ), which is a PI(4,5)P2 binding protein (Ye et al., 2018). In addition, ubiquitination of GPCRs has been shown to precede their $\beta$-arrestin2-BBSome mediated removal from cilia (Desai et al., 2020; Shinde et al., 2020). 
In addition to intrinsic membrane proteins, BBSome may regulate the removal of peripheral membrane and soluble proteins from cilia. In WT Chlamydomonas, the peripheral membrane protein Phospholipase D (PLD) is excluded from flagella. In BBS1,4, and 7 mutant Chlamydomonas PLD slowly accumulates in flagella (Lechtreck et al., 2013; Liu and Lechtreck, 2018). The soluble protein Carbonic anhydrase 6 (CAH6) is excluded from one of the two Chlamydomonas flagella. However, BBS1 mutant Chlamydomonas loses this asymmetry and CAH6 was found to be present in both flagella, suggesting the BBSome removes CAH6 selectively from one flagellum (Yu et al., 2020). Overall, these studies provide strong evidence that the BBSome complex is involved in removal of proteins from cilium and that the BBSome is a highly selective regulator of ciliary protein complement.

Retinal degeneration is the most common phenotype in BBS; almost all patients develop retinitis pigmentosa. BBS has, therefore, been intensely studied in the context of retinal degeneration. Animal and cell models, spanning unicellular organisms to non-human primates, have been developed to decipher the role of BBSome proteins in photoreceptor biology (Wingfield et al., 2018; Peterson et al., 2019). Knockout of BBSome proteins in mice recapitulates progressive degeneration of photoreceptors observed in human patients. Onset of degeneration varied among studies with mutations or knockouts of different BBSome proteins (Nishimura et al., 2004; Abd-ElBarr et al., 2007; Davis et al., 2007; Swiderski et al., 2007; Simons et al., 2011). In parallel to studies in primary cilia, recent studies have emphasized the role of the BBSome in removal of nonciliary proteins from the OS. Quantitative proteomic analysis of photoreceptor OS of WT and BBS17 mutant mice showed enrichment of 139 proteins in the OS of the mutant, including a 3-fold increase in Stx3 and Munc18-1/Stxbp, IS proteins involved in RTC fusion with periciliary membranes (Datta et al., 2015). Only eight proteins normally localized to the OS showed reduced OS localization. OS proteins, including Rhodopsin, peripherin2, PDE6 $\alpha, \beta$, and Rom-1, remained unchanged. Accumulation of Stx 3 in the OS was later confirmed in $\mathrm{BBS}^{-/-}, \mathrm{BBS}^{-/-}$, and $\mathrm{BBS}^{-/-}$mice as well (Hsu et al., 2017; Dilan et al., 2018). These results show that the BBSome, like in primary cilia and flagella, is a regulator of OS protein complement.

An important difference between photoreceptors and primary cilia or flagella, however, is the role of the BBSome in regulating the trafficking of GPCRs into and out of ciliary compartment. Rhodopsin content within the rod OS does not appear to be strongly regulated by the BBSome. While knockout of several BBSome proteins results in mislocalization of rhodopsin, it is important to note that this mislocalization is either incomplete, where the majority of rhodopsin properly localizes to the OS (Abd-El-Barr et al., 2007; Pretorius et al., 2010; Jiang et al., 2016), or is accompanied by major structural disruption, or complete absence of the OS (Nishimura et al., 2004; Abd-El-Barr et al., 2007; Simons et al., 2011). In the case where there is loss of the OS structure, it is impossible to ascertain if the mislocalization is due to rhodopsin transport deficits rather than from lack of the ciliary destination. In the case where there is slight mislocalization with the majority of rhodopsin properly localized to the OS, it is hard to make a case that the BBSome is playing a major role. There is good evidence that rhodopsin localizes to photoreceptor cilia via a mechanism distinct from that of other GPCR localization to primary cilia (Geneva et al., 2017). The c-terminal VxPx motif that is required for OS targeting of rhodopsin inhibits GPCR targeting to primary cilia (Geneva et al., 2017). This is not surprising since the VxPx motif is not recognized by the BBSome (Klink et al., 2017). Replacing the IC3 loop of rhodopsin with that of SSTR3 and removal of the c-terminal VxPx motif resulted in enhanced ciliary localization of the chimeric rhodopsin heterologously expressed in epithelial cells. A recent study has shown that the CTS within the IC3 loop of SSTR3 provides strong binding to a recombinant BBSome core complex, but that the IC3 loop of 5-HT-6 receptor, which is similar to that of rhodopsin, provided only weak interaction (Klink et al., 2017). This weak interaction, as well as the presence of an FR motif in rhodopsin helix 8, which also has weak affinity to the BBSome (Klink et al., 2017; Yang et al., 2020), may support the low presence of rhodopsin in primary cilia (Trivedi and Williams, 2010; Trivedi et al., 2012; Wang et al., 2012; Geneva et al., 2017; Chadha et al., 2019).

In conclusion, the role, if any, of BBSome in rhodopsin OS localization or removal is not clear. However, there is evidence that it plays a role in cone opsin transport to the COS (Abd-ElBarr et al., 2007; Bales et al., 2020).

\section{INTRINSIC MEMBRANE PROTEIN COMPARTMENTALIZATION WITHIN THE CILIARY ROD OUTER SEGMENT}

Compartmentalization of intrinsic membrane proteins within the photoreceptor OS is an extraordinarily demanding problem (Figure 5). It has been proposed that the OS serves as a default destination for membrane proteins; those that are localized elsewhere containing targeting information within their sequence and structure (Baker et al., 2008). Considering the sheer mass of proteins that must travel to the OS, this would seem to be an efficient and perhaps necessary mechanism. However, some membrane proteins contain specific ciliary localization sequences that are required for their transport to the OS (Mazelova et al., 2009; Salinas et al., 2013), suggesting the default pathway is not the only pathway.

There are two distinct secretory pathways involved in membrane protein trafficking, the conventional and unconventional pathways. The conventional pathway refers to proteins that are transported from the ER to the Golgi and bud off the Golgi into transport vesicles. Proteins going through the unconventional pathway exit the ER and bypass the Golgi. A convenient way to differentiate between these pathways is to examine sugars that are post translationally added to some proteins. Glycosylated proteins that take the conventional route acquire endoglycosidase $\mathrm{H}$ (Endo $\mathrm{H}$ ) resistance as they pass through the medial trans-Golgi (Rabouille et al., 1995). The conventional pathway accounts for the majority of proteins traveling to OSs including Rhodopsin (Nathans, 1992; Nickell et al., 2007), Rom1, the CNG $\alpha 1 / C N G \beta 1$ complex, PRCD, and 


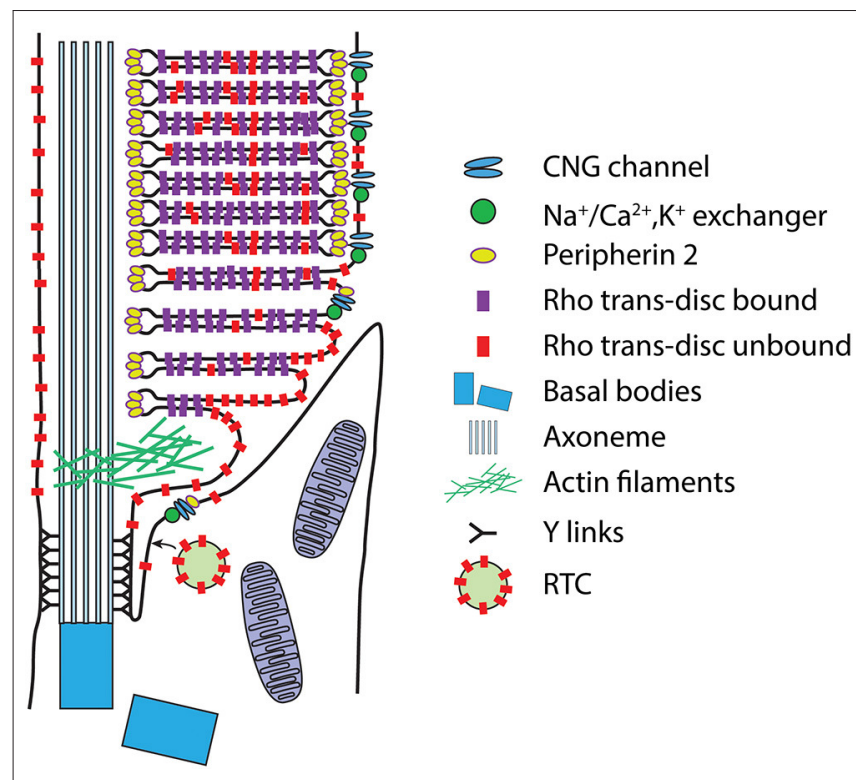

FIGURE 5 | Intrinsic membrane protein compartmentalization within the OS. Schematic of a mammalian rod in the region of the CC. Intrinsic membrane proteins are thought to be delivered to the apical/periciliary membrane on rhodopsin transport carrier (RTC) vesicles, where they fuse (see text for details). Membrane proteins then enter the CC/transition zone, possibly mediated by the BBSome. Proteins destined for disc and plasma membrane transport to the lamellar membranes most likely by diffusion. Eventually the nascent disc membranes are enclosed by the plasma membrane through a mechanism that separates plasma membrane proteins, the $\mathrm{CNG}$ gated channel- $\mathrm{Na}^{+} / \mathrm{Ca}^{2+}, \mathrm{K}^{+}$ exchanger complex, from the disc proteins, rhodopsin and peripherin 2, which likely occurs during peripherin 2-Rom1-mediated disc rim expansion (see text). Note that this schematic is not meant to be an exhaustive representation of all OS membrane protein transport, or of disc morphogenesis.

GC1. Both PRCD and GC1 require rhodopsin for their stability and trafficking to the OS (Pearring et al., 2015; Spencer et al., 2016). A recent study confirmed trafficking of GC1 through the conventional pathway (Pearring et al., 2020).

\section{Rhodopsin Transport and the Conventional Pathway to the Cilium Base}

Rhodopsin's VxPx motif is considered to be its primary localization signal and is required for binding to the small GTPase Arf4 (Deretic et al., 2005; Mazelova et al., 2009). Interestingly, VxPx may not be essential for OS localization of rhodopsin. A transgenic study expressing human rhodopsin in Xenopus found that there is a secondary signal in rhodopsin within amino acids 322-336 that is responsible for its mislocalization when the $\mathrm{VxPx}$ motif is absent (Lodowski et al., 2013). When both the primary and secondary signals are removed, rhodopsin again localizes to the OS, providing supporting evidence for the default OS trafficking pathway.

Rhodopsin trafficking from the Golgi to the periciliary membrane has been thoroughly studied and reviewed (Deretic and Wang, 2012; Wang and Deretic, 2014; Deretic et al., 2019) and will be covered briefly here. The Arf family of small GTPases are involved in various cellular processes including membrane trafficking (Donaldson, 2005). When activated by the
GEF GBF1, Arf4 can bind to the VxPx of rhodopsin (Wang et al., 2017). The Arf GAP ASAP1 then binds to rhodopsinArf4 and recruits Rab11a and FIP3 which aid in the GTP hydrolysis of Arf4 inactivating and dissociating Arf4 from the rhodopsin-ASAP1-Rab11a-FIP3 complex. Rabin8 is recruited to the developing vesicle and leads to the formation of the Rab11Rabin8-Rab8 module. The Rab11-Rabin8-Rab8 module recruits the SNARE component VAMP7 into the budding secretory vesicles, called rhodopsin transport carriers (RTCs) (Deretic et al., 2004; Wang and Deretic, 2014), making them competent for fusion with the plasma membrane near the base of the cilium containing the partner SNARE components syntaxin 3 and SNAP25 (Kandachar et al., 2018).

The role of the Arf4 pathway in rhodopsin transport is controversial. While the Arf4-based rhodopsin trafficking pathway has been extensively characterized in vitro and in amphibians (Deretic et al., 1998, 2005; Moritz et al., 2001; Mazelova et al., 2009; Wang et al., 2012, 2017; Wang and Deretic, 2015), recent studies have called the requirement of Arf4 into question. Conditional knockout of Arf4 in mouse photoreceptors had no effect on rhodopsin localization (Pearring et al., 2017). Additionally, removing Rab8a and Rab1la from the mouse retina individually or concurrently had no effect on OS protein localization or the ability of the mutant mice to respond to light as measured by ERG (Ying et al., 2016). In light of these results, it has been proposed that, in the mouse where the membrane trafficking requirements are lower, another Arf may be able to partially compensate (Wang et al., 2017). Alternatively, it has been speculated that another Arf pathway, perhaps utilizing Arf5, that is independent of Rab8a and Rab11a is operating in mouse (Ying et al., 2016). Further studies into rhodopsin trafficking pathways in mouse models will be necessary to resolve these discrepancies.

Rhodopsin's transport in RTCs from the Golgi to the base of the cilium is thought to require IFT20 which moves along microtubules (Keady et al., 2011), likely via KIFC1 (Kinesin family member C1) which has been shown to interact with ASAP1, or possibly dynein motors (Krock et al., 2009). Indeed, in cultured primary ciliary cells knockdown of $K i f c 1$ resulted in a lack of cilia formation and accumulation of ASAP1 and receptors Smo and SSTR3 at the Golgi (Lee et al., 2018b). IFT20 is somewhat different from other components of the canonical IFT-B anterograde complex as it is not solely localized to the base and length of the cilium, it is also found at the Golgi. IFT20 is likely an adaptor that binds rhodopsin and serves to transport the RTCs from the TGN to the base of the periciliary membrane (Keady et al., 2011). Cultured cells where Ift20 is knocked out fail to develop cilia (Follit et al., 2006; Takei et al., 2018), suggesting that IFT20's main role is likely in regulating ciliogenesis, maintenance of the cilium, and trafficking of ciliary components to the basal body.

\section{Rhodopsin Transport Across the Cilium Base and Within the Connecting Cilium}

Rhodopsin's mode of transport across the CC has yet to be determined. There are two main camps: The first is that RTCs 
themselves are transported through the CC via motor driven transport and fuse with nascent discs within the enclosed OS plasma membrane (Chuang et al., 2007; Gilliam et al., 2012). However, RTCs average 250-300 nm (Deretic and Papermaster, 1991; Deretic and Mazelova, 2009), making them far too large to pass through any part of the CC. Moreover, recent careful EM studies have clearly shown nascent discs to be open to the extracellular milieux (Burgoyne et al., 2015; Ding et al., 2015; Volland et al., 2015). Finally, immunogold labeling experiments have shown rhodopsin to be located in the ciliary membrane of mouse photoreceptors with little in the lumen of the cilium (Wolfrum and Schmitt, 2000; Burgoyne et al., 2015; Chadha et al., 2019).

The second camp posits that RTCs fuse with membranes at the periciliary ridge complex (Papermaster et al., 1986). It is then thought that rhodopsin is transported by IFT along the plasma membrane of the CC toward the site of disc formation (Krock and Perkins, 2008; Bhowmick et al., 2009). However, the sheer mass of rhodopsin that must be transported does not appear to support the IFT hypothesis. Ten percent of the OS of each rod is renewed daily (Besharse, 1986). Based on the total OS rhodopsin content of $3 \times 10^{9}$ molecules (amphibian) and $1 \times 10^{8}$ molecules (mammalian) (Pugh and Lamb, 2000), the rate of rhodopsin transport through the CC is on the order of 3500 molecules s ${ }^{-1}$ in the frog, and 100 molecules $\mathrm{s}^{-1}$ in mouse. Notably, it has been shown that disc morphogenesis and rhodopsin transport is not constant, but rather undergoes a burst of activity where $70 \%$ of new discs are formed within the first $8 \mathrm{~h}$ of daylight in frog (Besharse et al., 1977) and a smaller variation in delivery upon onset of darkness in mouse (Volland et al., 2015). Thus, within this time-period the rhodopsin delivery rate is closer to 7,300 molecules s$^{-1}$ in amphibians and 100-200 molecules s ${ }^{-1}$ in mouse. This would require high frequency IFT transport within the CC, and significant recycling of IFT complexes, for which there is no evidence.

Aside from the above quantitative argument, evidence for active transport of rhodopsin has been variable. KIF3A conditionally knocked out in mouse photoreceptors resulted in the mislocalization of opsin, leading to the conclusion that KIF3A, and by extension IFT, is essential for rhodopsin transport within the CC (Marszalek et al., 2000; Jimeno et al., 2006). In contrast, in another rod specific KIF3A knockout mouse rhodopsin and many of the other phototransduction proteins appeared to transport normally to the OS for 2-4 weeks, after which rods degenerated (Avasthi et al., 2009). Similarly, retina specific tamoxifen inducible deletion of KIF3A and IFT88 in adult mice showed normal localization of rhodopsin for 2 weeks before degeneration of photoreceptors while the same deletion from embryonic stage resulted in lack of assembly of the CC (Jiang et al., 2015b). Therefore, in rods, IFT does not appear to be essential for rhodopsin transport within the CC and opsin mislocalization is likely an indirect effect of the failure to properly form and maintain a cilium. Importantly knockout of KIF17, the only other known anterograde IFT motor, in conjunction with knockout of KIF3A in rods does not prevent rhodopsin trafficking to the ROS, thus showing that there is no compensatory expression of motors (Jiang et al., 2015a).
Interestingly, there was major mislocalization of phototransduction components in cone specific KIF3A knockout mice (Avasthi et al., 2009), and KIF3B dominant negative mutant causes accumulation of large vesicles in cone IS and disruption of cone OS morphogenesis (Insinna et al., 2009). These results suggest that IFT is required for transport of opsin and other phototransduction proteins in cones, but not in rods.

The majority of evidence, thus, seems to point to an IFT-independent rhodopsin transport mechanism in rods. We propose that diffusion along the ciliary membrane is the primary mode of rhodopsin transport within the CC. In support of this idea our lab has shown that rhodopsin transport is exclusively by diffusion when heterologously expressed in the primary cilia of IMCD 3 cells (Lee et al., 2018a). Indeed, SSTR3 and Smo receptors have also been shown to move mostly by diffusion in IMCD3 cilia (Ye et al., 2013; Lee et al., 2018a). With an average diffusion coefficient of $0.23 \mu \mathrm{m}^{2} \mathrm{~s}^{-1}$ along the ciliary membrane (Lee et al., 2018a), a rhodopsin molecule could traverse a $1 \mu \mathrm{m}$ long CC in $\sim 2 \mathrm{~s}$, easily rapid enough to account for rhodopsin delivery to nascent discs. Together, these studies have thrown the notion that GPCRs transport exclusively by IFT within cilia into question.

It is well-documented that the density of rhodopsin is $\sim$ twofold higher in the disc membranes than in the OS plasma membrane (Molday and Molday, 1987), which is contiguous with the CC membrane. This raises the question of what is the driving force behind concentrating rhodopsin in the discs if IFT is not involved? One enticing possibility is that rhodopsin is drawn to the nascent discs by a binding sink created during disc elaboration. Rhodopsins are thought to form dimers between adjacent nascent disc membranes (Fliesler et al., 1985; Hubbell et al., 2003; Murray et al., 2009), interacting at their extracellular faces, which may enhance close juxtaposition of extracellular membranes by "Velcroing" them together (Figure 6). The propensity for rhodopsins to form cis dimers (Ploier et al., 2016; Zhang et al., 2016b), within the same disc membrane, may further drive concentration by recruiting rhodopsins into higher order oligomers.

\section{Peripherin 2 and the Unconventional Pathway}

Proteins transported via the unconventional secretory pathway exit the ER-Golgi prior to glycosylation modifications that take place in the medial to trans-Golgi apparatus (Tian et al., 2014). Peripherin 2, a tetraspanin protein that is localized to the rims of discs (Figure 5) and is required for proper OS formation, appears to be transported through the unconventional pathway. Ciliary targeting of peripherin 2 is dependent on COPII-mediated exit from the ER (Tian et al., 2014) and appears to require a signal in the C-terminus that includes Valine 332 (Tam et al., 2004; Salinas et al., 2013, 2017; Molday and Goldberg, 2017; Conley et al., 2019a). Peripherin 2 transport also appears to require interactions with SNARE machinery (Zulliger et al., 2015) and may be trafficked to the OS through a mechanism involving the late endosome (Otsu et al., 2019). However, peripherin 2 appears to take the conventional route $\sim 30 \%$ of the time in mice, likely via hetero-oligomerization with rom-1 (Conley et al., 
2019b). Until recently, peripherin 2 was the only OS-destined protein identified that is transported through the unconventional pathway. However, evidence suggests that R9AP traffics to the OS independently of rhodopsin, suggesting that it may transport via the unconventional secretory pathway (Pearring et al., 2014) and a recent study has shown that $\mathrm{ABCA} 4$ also traffics via the unconventional pathway (Pearring et al., 2020).

\section{ROLES OF PHOSPHOINOSITIDES IN PROTEIN ENRICHMENT IN THE PHOTORECEPTOR CILIUM}

Phosphoinositide phospholipids are known to be important for various cellular processes, creating specialized membrane compartments, recruiting proteins with phosphoinositide binding capacities, trafficking of membrane proteins, and serving as precursors for cellular second messengers. For a comprehensive review of phosphoinositides in the context of the retina, see (Wensel, 2020). Here we will focus on PI4P and $\mathrm{PI}(4,5) \mathrm{P}_{2}$, the two most abundant phosphoinositides in photoreceptors (Finkelstein et al., 2020).

PI4P is enriched in the Golgi via dephosphorylation of $\mathrm{PI}(4,5) \mathrm{P}_{2}$ and $\mathrm{PI}(3,4) \mathrm{P}_{2}$ or phosphorylation of PtdIns (De Matteis et al., 2002; Liu and Bankaitis, 2010) and is thought to be important in trafficking through and vesicle budding from the Golgi and vesicular trafficking to the plasma membrane (Godi et al., 2004; Lenoir and Overduin, 2013). While PI4P is the predominant phosphoinositide present in the Golgi, there is also a small pool of $\mathrm{PI}(4,5) \mathrm{P}_{2}$.

Ezrin and moesin interact with transmembrane proteins, PDZ-containing proteins, the cytoskeleton, and bind membranes via $\mathrm{PI}(4,5) \mathrm{P}_{2}$ (Bretscher et al., 2002). These shared functions indicate they may be important in the trafficking of membrane proteins. In support of this notion, both ezrin and moesin were shown to be present on RTCs, particularly at the site of vesicle docking near the IS/OS junction (Deretic et al., 2004). Altering biosynthesis of acidic phospholipids ultimately resulting in the hydrolysis of $\mathrm{PI}(4,5) \mathrm{P}_{2}$ led to a reduced association of ezrin and moesin with RTCs and interfered with RTC docking and fusion at the base of the CC (Deretic et al., 2004).

A mouse at Jackson Laboratories named tubby had a spontaneous mutation and an obesity phenotype (Coleman and Eicher, 1990). The tubby gene product is expressed in the brain and retina, and tubby mice have both retinal and cochlear degeneration (Ohlemiller et al., 1995) and reduced fertility (Ohlemiller et al., 1998). At least four other tubby-like proteins (TULPs) have since been identified that contain a conserved Cterminal tubby domain which can interact with $\operatorname{PtdIns}(3,4) \mathrm{P}_{2}$, $\operatorname{PtdIns}(4,5) \mathrm{P}_{2}$, and PtdIns $(3,4,5) \mathrm{P}_{3}$ (Santagata et al., 2001). Tubby proteins interact with the plasma membrane by binding $\mathrm{PI}(4,5) \mathrm{P}_{2}$ and are released when $\mathrm{PI}(4,5) \mathrm{P}_{2}$ is hydrolyzed (Santagata et al., 2001). It has been demonstrated that activation of $\mathrm{G} \alpha_{\mathrm{q}}$ causes tubby to leave the plasma membrane via a PLC- $\beta$ mediated mechanism of $\mathrm{PI}(4,5) \mathrm{P}_{2}$ hydrolysis (Santagata et al., 2001).

Tulp1 is exclusively found in photoreceptors, thus it is no surprise that tulp1 mice have retinal degeneration but lack the

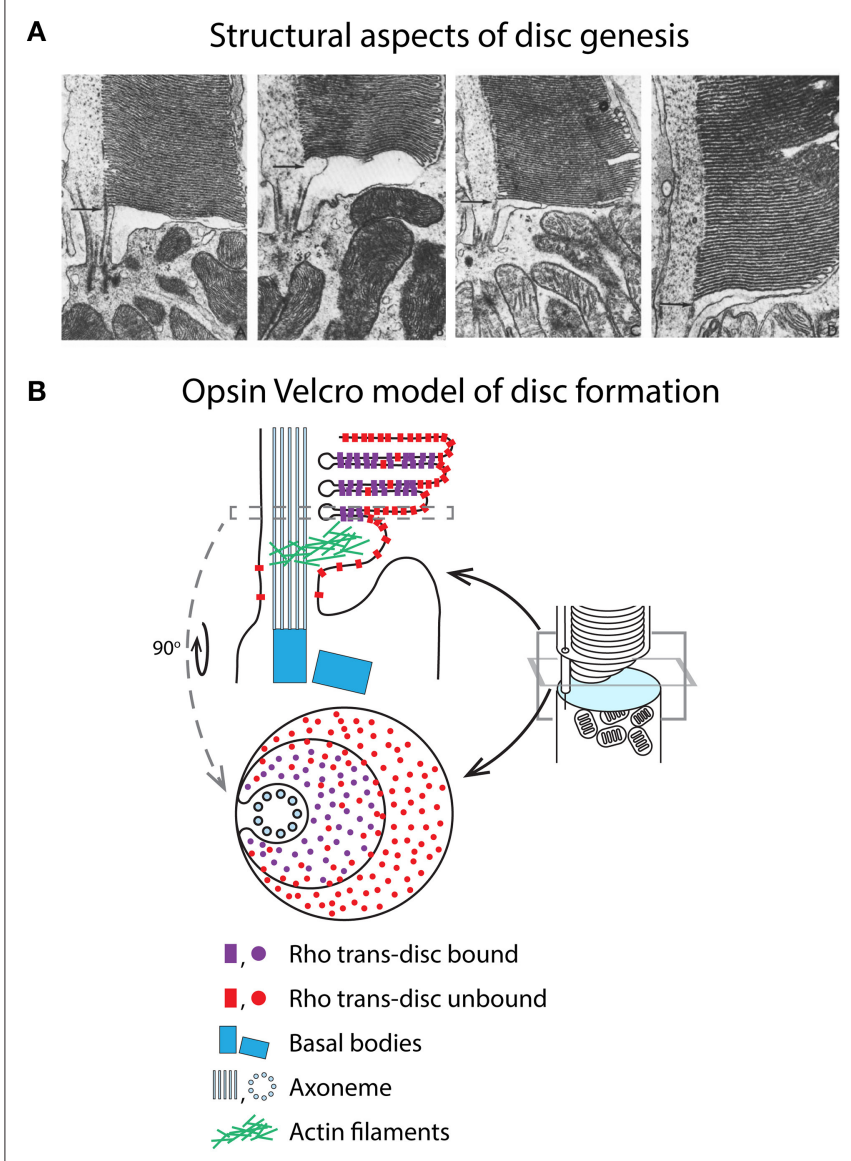

FIGURE 6 | The opsin Velcro model of rhodopsin enrichment in disc membranes. (A) Series of transmission EM images showing how nascent disc morphogenesis is thought to proceed. Note the close juxtaposition ( 2-3 nm) of extracellular membrane leaflets between the previous and new lamellae as the membrane of the new lamella elongates. Reproduced from Steinberg et al. (1980). (B) Rhodopsin density in the disc membranes is twice that in the plasma membrane, indicating that it is not efficiently separated into disc membranes. One possible explanation for this asymmetry is that rhodopsin self-associates at is extracellular $\mathrm{N}$-termini. This may result in a Velcro-like coupling of the nascent disc membranes and producing a self-binding sink driving disc enrichment. Affinity would not be expected to be high for this interaction since it only produces a twofold difference in disc vs. plasma membrane density. This interaction may also help drive disc morphogenesis. For simplicity, rhodopsin cis dimers (in the same membrane) are not depicted in this schematic.

cochlear defects and the obesity phenotype seen in tubby mice (Ikeda et al., 2000). Mutations in TULP1 contribute to $~ 5 \%$ of total RP cases ( $\mathrm{Gu}$ et al., 1998) and tulp1 mice accumulate vesicles in the interphotoreceptor matrix (Hagstrom et al., 1999) similar to those seen in the $r d s$ and $p c d$ mouse. TULP1 interacts with F-actin (Xi et al., 2005) and dynamin (Xi et al., 2007) in photoreceptors, suggesting that it may play a role in vesicular trafficking to the periciliary plasma membrane. Similar functions have been identified for TULP3 in primary cilia where RNAi knockdown of TULP3 decreased trafficking of some GPCRs to cilia without affecting ciliogenesis. The interaction of TULP3 
with IFT-A and phosphoinositides is required for trafficking of particular GPCRs to cilia (Badgandi et al., 2017), and it has been shown that Tub and TULP2 can also bind IFT (Mukhopadhyay et al., 2010). Knockdown of the inositol polyphosphate 5' phosphatase INPP5E which plays a role in the enrichment of PI4P in the ciliary membrane via dephosphorylation of $\mathrm{PI}(4,5) \mathrm{P}_{2}$ leads to an accumulation of TULP3-dependent GPCR cargo in primary cilia (Badgandi et al., 2017).

INPP5E is also present in photoreceptors. Interestingly, INPP5E's localization in photoreceptors seems to be different from that documented for other ciliated cell types. Studies in primary cilia have shown INPP5E localization in the cilia, co-localizing with axonemal staining (Bielas et al., 2009; Jacoby et al., 2009). However, in photoreceptors INPP5E appears to be absent from the cilium, concentrated near the Golgi and proximal IS and does not appear to overlap with staining for centrin (Bielas et al., 2009; Hanke-Gogokhia et al., 2016). This is somewhat curious as INPP5E's localization in primary cilia is suggested to rely on the lipid binding chaperone $\operatorname{PrBP} \delta$ which is also present in photoreceptors and is important for the OS localization of PDE6 and GRK1 (Zhang et al., 2007). It could be that another PI 5-phosphatase resides in the photoreceptor cilium in order to maintain low levels of $\mathrm{PI}(4,5) \mathrm{P}_{2}$ and higher levels of $\mathrm{PI}(4) \mathrm{P}$. While PI(4)P is seen in both the IS and OS of photoreceptors, $\mathrm{PI}(4,5) \mathrm{P}_{2}$ appears to be mostly excluded from the OS (Finkelstein et al., 2020), suggesting photoreceptors possess a mechanism for either enzymatically removing or excluding $\mathrm{PI}(4) \mathrm{P}_{2}$ from the OS, similar to primary cilia. The PI 5-phosphatase ORCL (Oculocerebrorenal syndrome) is mutated in Lowe and Dent syndromes and was shown to localize to the OS of zebrafish photoreceptors (Luo et al., 2012). Perhaps photoreceptors have developed a system where ORCL and possibly other phosphatases work to remove $\mathrm{PI}(4,5) \mathrm{P}_{2}$ from ciliary membrane and OS.

\section{TARGETING OF OUTER SEGMENT PLASMA MEMBRANE PROTEINS}

Unlike the bulk of the phototransduction machinery that are mostly localized to the discs, two key proteins, the CNG channel and the $\mathrm{Na}^{+} / \mathrm{Ca}^{2+}, \mathrm{K}^{+}$exchanger, which are found in a complex (Molday and Molday, 1998), are localized to the OS plasma membrane (Figure 5), raising the question of whether they use OS transport mechanisms that are distinct from the disc membrane destined proteins. The CNG channel is a heterotetramer consisting of three $\alpha 1$ and one $\beta 1$ subunits (Weitz et al., 2002; Zheng et al., 2002; Zhong et al., 2002). The $\beta 1$ subunit contains a glutamic acid rich GARP domain that binds to the tetraspanin protein, peripherin 2 (Poetsch et al., 2001), which itself is localized to the disc rims, thus providing structural stabilization between discs and the plasma membranes and confining the position of the CNG channels along the OS plasma membrane. The OS localization of the CNG $\beta 1$ subunit appears to rely on its glutamic acid rich GARP domain (Nemet et al., 2014). CNG interaction with peripherin 2 occurs within the IS (Ritter et al., 2011) and CNG $\beta 1$ is not located in vesicles found in the subretinal space of mouse rods lacking peripherin 2
(Spencer et al., 2019), leading to the speculation that trafficking of the CNG channel complex relies on association with peripherin 2. CNG channels are mislocalized to the IS in mouse rods lacking the endocytic adapter proteins Numb and Numb-like, which may redirect $\mathrm{CNG} \alpha 1$ to endosomes (Ramamurthy et al., 2014).

However, a recent study claims to cast doubt on the role of peripherin 2 for $\mathrm{CNG}$ channel trafficking to the OS (Pearring et al., 2020). This study showed that CNG channels are delivered via the conventional secretory pathway, whereas peripherin 2 is delivered exclusively through the unconventional pathway (Tian et al., 2014). They show that the GARP domain possesses separate OS targeting sequence and peripherin 2 interaction domains. However, it cannot be ruled out that the Numb-mediated direction of the CNG channel to the late endosome, where transport pathways of CNG channels and peripherin 2 are thought to cross (Ramamurthy et al., 2014; Otsu et al., 2019), was disrupted by generating probes that only possessed specific domains.

In addition to trafficking to the OS, rod photoreceptor proteins must undergo an additional sorting between the disc membranes and the plasma membrane. A major unanswered question is how this separation occurs. It has been speculated that disc-plasma membrane protein sorting of CNG channels and the $\mathrm{Na}^{+} / \mathrm{Ca}^{2+}, \mathrm{K}^{+}$transporter occurs when discs are enclosed within the plasma membrane (Spencer et al., 2020), presumably by a peripherin 2-Rom1-dependent mechanism (Conley et al., 2019b). However, more work is needed to support this idea.

Finally, disc and plasma membranes have distinct phospholipid content that may contribute to protein sorting between these membrane domains (Fliesler and Anderson, 1983; Albert and Boesze-Battaglia, 2005). Disc membranes contain equal amounts of PE and PC at 42 and 45\%, respectively and $14 \%$ PS. the plasma membrane contains $10 \%$ PE, $65 \%$ PC, and $24 \%$ PS. Fatty acyl side chains are also highly divergent, with a ratio of 22:6 DHA in the disc vs. plasma membranes. The plasma membrane is enriched in cholesterol at 30 mole\% relative to newly made discs which contain $0.3 \mathrm{~mol} \%$ (Albert and Boesze-Battaglia, 2005). How phospholipid content is sorted between disc and plasma membrane is not understood.

\section{PERIPHERAL MEMBRANE PROTEIN COMPARTMENTALIZATION WITHIN THE ROD OUTER SEGMENT}

Peripheral membrane proteins reversibly interact with membranes, establishing an equilibrium between soluble and membrane bound states and are constantly in flux between the two. Membrane affinity is set by a number of physical factors, including hydrophobic, electrostatic, protein-protein and other binding interactions, alone or in combination. The majority of phototransduction components, including transducin, PDE6, GRK1, recoverin, RGS9, and G $\beta 5 \mathrm{~L}$ are peripheral membrane proteins that are mostly localized to the OS. Some of these proteins undergo light-dependent redistribution from the OS to the IS (Calvert et al., 2006). Owing to the relative impermanence of membrane association, compartmentalization 
requires mechanisms in addition to the secretory pathways already discussed.

\section{Lipid Binding Chaperone Proteins Drive Outer Segment Localization of Some Peripheral Membrane Proteins}

There are multiple lipid binding proteins present in photoreceptors, the most well-studied of which are $\operatorname{PrBP} \delta$ (Norton et al., 2005) and Unc119a/b (Liu et al., 2007; Zhang et al., 2011a). $\operatorname{PrBP} \delta$ is a prenyl binding protein with similar structural features to other lipid binding proteins, including Unc119 and RhoGDI (Zhang et al., 2007). IHC shows that $\operatorname{PrBP} \delta$ is distributed throughout the photoreceptor. Labeling was significantly more intense in the IS extending to the synapse (Zhang et al., 2007). PrBP $\delta$ is thought to drive solubilization of prenylated proteins by depleting the soluble fraction, rather than extracting them from the membrane (Qureshi et al., 2018). It is required for the proper OS localization of PDE6 and for the stability of GRK1 (Zhang et al., 2007). The $\alpha$ and $\beta$ subunits of PDE6 are farnesylated and geranylgeranylated, respectively (Anant et al., 1992) and GRK1 is farnesylated (Inglese et al., 1992).

Prenylation is required for $\operatorname{PrBP} \delta$ binding to peripheral membrane proteins (Zhang et al., 2004). Prenyl moieties, however, possess different numbers of prenyl repeats, farnesyl with three and geranylgeranyl with four. This raises the question of whether PrBP $\delta$ prefers binding to one over the other. Studies that have addressed this question have conflicting results. A direct binding study using recombinant proteins showed that $\operatorname{PrBP} \delta$ affinity for farnesylated GRK1 was $\sim 30$-fold higher than for geranylgeranylated GRK7 (Zhang et al., 2004). In contrast, mutation of the c-terminal leucine in the RPGR (retinitis pigmentosa GTPase Regulator) CAAX motif to methionine, which changes the c-terminal prenyl from a geranylgeranyl to a farnesyl, resulted in reduced ciliary localization, suggesting that $\operatorname{PrBP} \delta$ has a lower affinity for the farnesyl moiety (Rao et al., 2016). A significant caveat to these studies, however, is that the extent of lipidation of these proteins was not clear. Moreover, carboxymethylation of prenylated proteins is another important modification (Inglese et al., 1992) that may influence the affinity of $\operatorname{PrBP} \delta$ for prenylated proteins or the prenylated proteins for membranes and it is not clear what the methylation state was in these studies. Finally, variation in c-terminal sequences of the proteins may modulate affinity.

Unc119a is an acyl binding protein whose distribution in photoreceptors is primarily IS and synaptic with a small amount in the OS. It has been shown to bind both rod and cone $\mathrm{T} \alpha$ (Zhang et al., 2011a) and has been implicated in the light-dependent transport of T $\alpha$ between OS and IS. T $\alpha$ return to the OS upon transition from light to darkness is impaired in Unc119a knockout mice, but the transport from the OS to the IS upon transition from darkness to light is unaffected (Zhang et al., 2011a), suggesting that Unc119a is needed for transport to the OS but not for transport out. It is estimated that Unc119a is expressed in a molar ratio of 1:4 Unc119a:Transducin $\alpha$ (Sinha et al., 2013). Interestingly, Unc119a expression is reduced 2-fold in the GNAT1 ${ }^{-/-}\left(\mathrm{T}^{-/-}\right)$mouse (Sinha et al., 2013), suggesting there is a feedback on Unc119a expression based on acylated protein load. Efficient binding of Unc119a to Ta required $\mathrm{N}$-terminal acylation as well as a peptide sequence, GAGASAEEKH, adjacent to the lipidation site (Zhang et al., 2011a). Unc119a, however, is not solely an acyl binding protein. It interacts with a number of non-lipidated proteins, including the SH2 and SH3 domains of some Src tyrosine kinases (Cen et al., 2003), Arl2 (Kobayashi et al., 2003), Arl3 (Veltel et al., 2008), CaBP4 (Haeseleer, 2008), and the synaptic protein RIBEYE (Alpadi et al., 2008).

A recent study showed that Unc119 expression levels in photoreceptors are influenced by its phosphorylation/ dephosphorylation by casein kinase 2 (CK2) and the calcium regulated calcineurin (Chaya et al., 2019). The phosphorylation state of Unc119 affects its interaction with cullin 3-kelchlike 18 (Cul3-Klhl18) ubiquitin E3 ligase, which ubiquitinylates unphosphorylated Unc119, leading to its degradation. Unc119 levels were found to decrease in dark-adapted photoreceptors and knockout of Klhl18 resulted in reduced photoreceptor sensitivity, as determined with scotopic ERG, suggesting that the translocation of transducin $\alpha$ into the OS was reduced. Immunohistochemistry showed the T $\alpha$ but not $\mathrm{T} \beta \gamma$ levels were higher in the ISs of Klhl18 ${ }^{-/-}$mice. These results are suggested to potentially be of therapeutic relevance since FK506 and cyclosporine A, drugs that inhibit calcineurin, were protective of photoreceptor light damage.

AIPL1 is another putative lipid binding chaperone protein operating in rods (Sokolov et al., 2019). AIPL1 mutations are linked to LCA and affects both rods and cones (Sohocki et al., 2000). It has been shown to specifically bind farnesylated proteins in a yeast two hybrid study (Ramamurthy et al., 2003). AIPL1 ${ }^{-/}$mouse expresses PDE6 subunits but they don't assemble properly and are likely degraded (Kolandaivelu et al., 2009). Recent results suggest that AIPL1 cooperates with PDE6r subunit to catalyze proper PDE folding (Yadav et al., 2019). Thus, although apparently not directly involved in peripheral membrane transport, AIPL1 is key for PDE6 function in the rod OS.

Compartmentalization of peripheral membrane proteins that associate with lipid binding chaperones requires cargo displacement factors that release them, allowing association with destination membranes (Wright et al., 2011; Hanke-Gogokhia et al., 2016). The cargo displacement factors are the small GTPase ADP ribosylation factor-like proteins Arl2 and Arl3. Both Arl2 and Arl3 can displace cargo from $\operatorname{PrBP} \delta$, but only Arl3 can displace cargo from Unc119a (Ismail et al., 2012). Arl2 and Arl3 release cargo when in the GTP bound state, GTP binding to Arl3 is catalyzed by the guanine nucleotide exchange factor (GEF) Arl13b (Gotthardt et al., 2015; Zhang et al., 2016a). Upon release, the GTPase accelerating protein (GAP) Rp2 accelerates hydrolysis of the Arl3 bound GTP to GDP (Veltel et al., 2008; Evans et al., 2010). The GEF and GAP for Arl2 have not been identified.

Arl3 is found throughout the cell body and possibly in the CC, but is absent from the OS (Grayson et al., 2002; Hanke-Gogokhia et al., 2016; Wright et al., 2016). Rp2 is found throughout the 
cell body, where it is enriched on the basal bodies, perinuclear region, synapse and the periciliary membrane of photoreceptors (Evans et al., 2010; Holopainen et al., 2010), where membrane association is thought to be mediated by myristoylation (Evans et al., 2010). Arl3 KO in both retina and rod showed that Arl3 is important for ciliogenesis and ciliary maintenance as well as efficient localization of lipidated proteins such as PDE6, GRK1, $\mathrm{T} \alpha$, and $\mathrm{T} \beta \gamma$ to the OS (Hanke-Gogokhia et al., 2016).

In addition to releasing cargo from $\operatorname{PrBP} \delta, \operatorname{Arl} 2$ binds to BART/Arl2BP and is thought to recruit it to the basal bodies and periciliary membranes where it appears to be important for ciliogenesis and cilium maintenance (Davidson et al., 2013; Moye et al., 2018). Arl2 also binds tubulin specific chaperone cofactor D and is, thus, thought to regulate heterodimerization of $\alpha$-, and $\beta$ tubulin (Bhamidipati et al., 2000). Arl2 is thought to be important for MT formation by regulating the soluble pool of tubulin, and thus is important for ciliary stability and control of axoneme length (Wright et al., 2018).

Arl13b is localized to the OS with enrichment in the proximal region (Hanke-Gogokhia et al., 2017; Dilan et al., 2019) and membrane association is mediated by double N-terminal palmitoylation (Roy et al., 2017). Retina specific mutations or deletions of Arl13b, which cause Joubert syndrome (Cantagrel et al., 2008), have a more severe phenotype than those impacting Arl3 (Hanke-Gogokhia et al., 2016). Retina specific Arl13b ${ }^{-/-}$ mice fail to form photoreceptor OSs and have improperly localized basal bodies (Dilan et al., 2019). Depletion of Arl13b in adult mouse rods causes accumulation of IFT88 at the proximal end of the cilia as well as mislocalization of Rhodopsin. Interestingly, PDE6, GRK1, and transducin localization are not affected, suggesting they transport to the ciliary photoreceptor OS in an Arl13b-independent way.

\section{Electrostatic Interactions and Peripheral Membrane Protein Compartmentalization}

The model whereby lipid-binding chaperone proteins mediate transport of peripheral membrane proteins to the ciliary compartment implicitly or explicitly assumes that association with the lipid binding chaperones is required to enter the ciliary compartment and that tight membrane binding underlies the retention in the target compartment. Recently we showed in Xenopus rods that $\operatorname{PrBP} \delta$ and Unc119 are not required for OS enrichment of all prenylated or acylated proteins (Maza et al., 2019). Moreover, using fluorescence recovery after photoconversion (FRAP) we showed that strong affinity of peripheral membrane proteins to target membranes is not required for compartmental enrichment. These results show that the basic distribution of peripheral membrane proteins in photoreceptors may be governed by diffusion and local binding and that the known lipid binding chaperones are not required for entry into the cilium (Figure 7). Although other, yet to be identified chaperone proteins cannot be ruled out, mass spectrometry analysis of pulldowns with lipidatedGFP probes did not identify obvious candidates (Maza et al., 2019). Compartment specific variation in membrane surface charge, protein content, ions as well as the lipid moiety and surface charge of the protein itself, therefore, may lead to differential compartmentalization of PMPs in photoreceptors, and presumably in primary cilia in general.

In (Maza et al., 2019) we also showed that a probe that consisted of EGFP and the c-terminal 18 amino acids of GRK1, which binds $\operatorname{PrBP} \delta$ when farnesylated, are sufficient to drive effectively exclusive OS localization, despite the probe having relatively low membrane affinity. A probe with a neutral amino acid peptide linker bearing C-terminal farnesylation motif but that did not bind $\operatorname{PrBP} \delta$ did not localize to the OS to nearly the same extent (Figure 7B, compare Far0 to GRK1ct18). This shows that the role of the lipid binding chaperone proteins is to tilt the equilibrium distribution of peripheral membrane proteins toward a specific compartment, rather than to deliver them to membranes where they bind with high affinity. There is a significant advantage to this mechanism. It allows peripheral membrane proteins within the OS, like GRK1, to equilibrate along the length of the OS, leading to equal numbers on each disc and, thus, uniform light responses throughout the OS. Indeed, amplitudes of dim light flashes are approximately uniform along the length of amphibian rod OSs (Baylor et al., 1979). Moreover, the localization to the OS is achieved without the non-specific blockade of the CC that would result from a soluble protein diffusion barrier.

\section{Lipid Switch Proteins}

The distribution of some lipidated proteins in photoreceptors appears to rely on interactions that sequester lipid moieties into hydrophobic folds within the proteins themselves. $\mathrm{T} \beta \gamma$ is a constitutive dimer with $\mathrm{T} \gamma$ bearing a farnesyl moiety (Fukada et al., 1990; Lai et al., 1990). Farnesylation of T $\gamma$ is required for OS localization of the T $\beta \gamma$ dimer (Brooks et al., 2018). While PrBP $\delta$ has been implicated in proper $\mathrm{T} \beta \gamma$ transport to the OS (Zhang et al., 2007), there is no published evidence for its involvement in light-dependent transport. Light-dependent transport of T $\beta \gamma$ appears to be disrupted by knockout of phosducin (Sokolov et al., 2004), a phosphoprotein in rods that undergoes light-dependent dephosphorylation and associates with T $\beta \gamma$ (Lee et al., 1987). Phosducin is phosphorylated by casein kinase 2 (CK2) in darkness (Humrich et al., 2003) and is dephosphorylated by protein phosphatase 2A in light (Brown et al., 2002). Phosducin appears to modulate the solubility of $\mathrm{T} \beta \gamma$ through an interaction dependent sequestration of the T $\gamma$ farnesyl moiety between the $\beta$ propeller blades 6 and 7 of T $\beta$ (Gaudet et al., 1996; Loew et al., 1998), rather than direct binding to the lipid. Thus, phosducin operates a lipid switch on T $\beta \gamma$. Despite the clear evidence that phosducin is involved in light dependent transport of $\mathrm{T} \beta \gamma$, there is no evidence that this transport impacts photoresponse kinetics or photoreceptor sensitivity (Sokolov et al., 2004; Krispel et al., 2007).

The calcium binding protein, recoverin, modulates GRK1 activity in a calcium and, thus, light dependent manner (Kawamura, 1993; Kawamura et al., 1993; Calvert et al., 1995; Chen et al., 1995; Klenchin et al., 1995). Knockout of recoverin in mouse rods shows that regulation of GRK1 leads to a moderate feedback control of light dependent PDE6 activity (Makino et al., 2004). Recoverin is N-terminally acylated (myristoylated) 


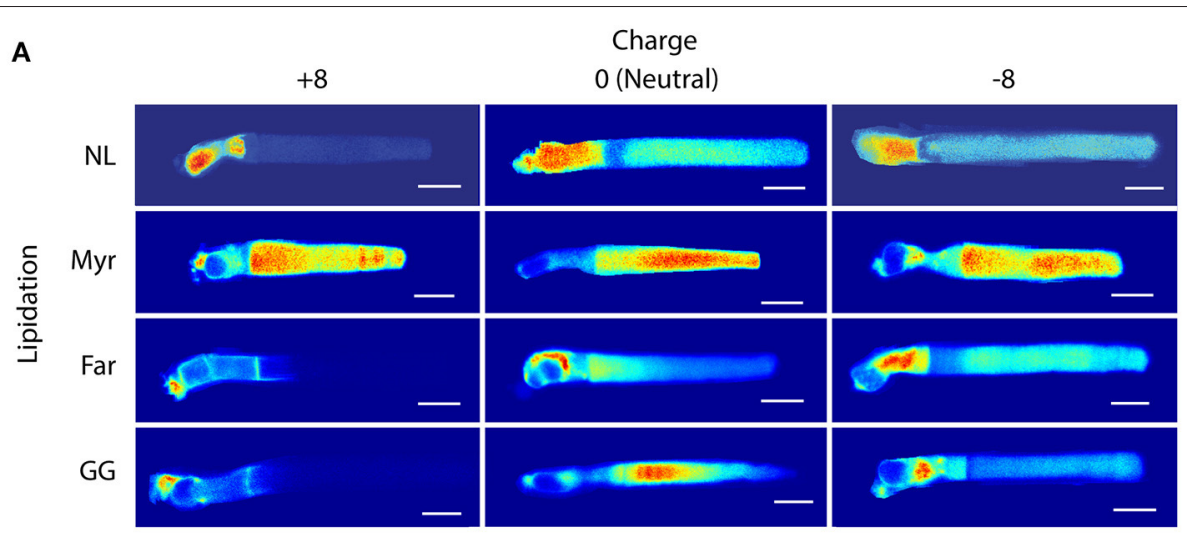

B

Synapse /OS

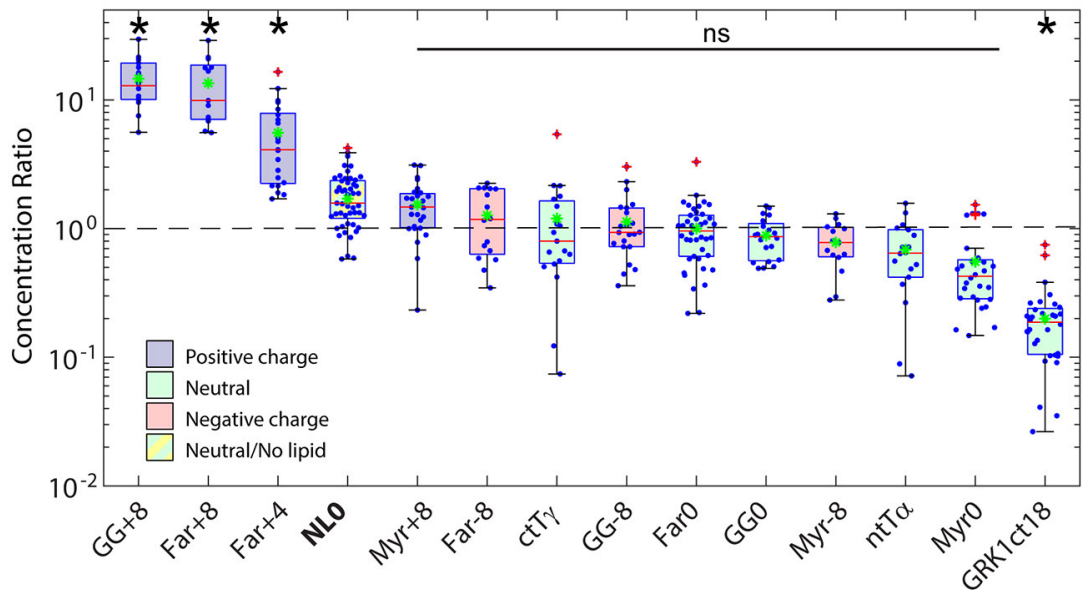

FIGURE 7 | Role of electrostatic interactions in the compartmentalization of peripheral membrane proteins. (A) Montage of confocal images of living Xenopus rods expressing EGFP probes with indicated surface charge and lipidation motif. Note that none of the probes possess binding motifs for the lipid binding chaperone proteins, PrBP $\delta$ and Unc119. Significant OS localization of most probes shows that lipid binding chaperone proteins are not required for OS access and enrichment of peripheral membrane proteins. (B) Box-whisker plots of average fluorescence in the pre-synapse divided by average fluorescence in the OS shows that positively charged probes with prenyl lipids are depleted from the OS and enriched in the pre-synapse, while probes containing myristoylation and neutral or negative charge equally distributed between compartments. A probe consisting of EGFP fused to the myristoylation motif containing N-terminal 16 amino acids of T $\alpha$, which binds to Unc119, was not significantly more OS enriched than the MyrO probe, which does not bind Unc119, suggesting that Unc119 association alone is not sufficient for OS enrichment. The probe containing the farnesylated C-terminus of GRK1, which does bind to PrBP $\delta$, is more strongly OS localized, thus, PrBP $\delta$ tilted the equilibrium toward OS enrichment. However, presence of the FarO probe in the OS shows that PrBPS is not required for OS entry. Modified from Maza et al. (2019).

(Dizhoor et al., 1992). The acyl moiety is folded into a hydrophobic cleft on recoverin when calcium free (Tanaka et al., 1995), and extends into the bulk aqueous phase when $\mathrm{Ca}^{2+}$ bound (Ames et al., 1995b), through a mechanism known as the calcium-myristoyl switch (Zozulya and Stryer, 1992). The myristoyl moiety induces cooperativity in calcium regulation of GRK1 (Ames et al., 1995a; Calvert et al., 1995). Recoverin undergoes a modest light-dependent redistribution in mouse rods (Strissel et al., 2005), however Unc119a does not bind to recoverin (Zhang et al., 2011a), suggesting that the lightdependent redistribution is likely the result of changes in calcium concentrations and diffusion of recoverin in the calcium free state. Thus, the distribution of some peripheral membrane proteins relies on self-sequestration of lipid moieties as a result of specific binding interactions, and diffusion.

\section{SOLUBLE PROTEIN COMPARTMENTALIZATION IN PHOTORECEPTORS}

The most abundant soluble protein in rod photoreceptors, arrestin-1 (Arr1), is nearly equimolar to rhodopsin (Strissel et al., 2006; Song et al., 2011). The distribution of Arr1 in rods changes in response to light (Broekhuyse et al., 1985; Whelan and McGinnis, 1988; Peterson et al., 2003, 2005; Nair et al., 2005; Strissel et al., 2006). In dark-adapted photoreceptors, more than $90 \%$ of Arr1 is found in the IS. When exposed to bright light, $80 \%$ of Arr1 is found in the OS, where it binds to light-activated, phosphorylated rhodopsin, preventing further activation of the phototransduction cascade. The prevailing thought is that light-activated, phosphorylated rhodopsin serves as a binding 
sink to draw Arr1 into the OS. The role of phosphorylation of light activated rhodopsin, however, was brought into question when it was observed by the Chen group that Arr1 translocation in response to light was partially maintained in GRK1 knockout mice and mice where rhodopsin phosphorylation sites were mutated, which led to the speculation that Arr1 transport to the OS upon light exposure was mediated by an active, motor-driven mechanism (Mendez et al., 2003; Zhang et al., 2003). However, the sheer mass of Arr1 molecules moving to the OS in response to light, $\sim 2$ billion molecules in amphibian and $\sim 75$ million in mammalian rods, with a halftime of $\sim 9-18$ min (Peterson et al., 2003; Strissel et al., 2006), makes motor-driven transport to the OS unlikely (Calvert et al., 2006). The experiments by the Chen group were carried out under conditions that likely activated the entire pool of rhodopsin in the rods and, although the affinity of arrestin for light-activated unphosphorylated rhodopsin is $\sim 35 \%$ of that for light-activated phosphorylated rhodopsin, it is $\sim 8$-fold higher than for dark-adapted rhodopsin (Nair et al., 2005). The study by Nair et al., that examined Arr1 localization to the OS at more moderate light intensities, showed that Arr1 transport to the OS, although present, was reduced in the GRK1 $1^{-/-}$and rhodopsin phosphorylation mutant mice (Nair et al., 2005). Moreover, Nair et al. showed that light dependent Arr1 transport was resistant to ATP depletion, suggesting that it is energy independent (Nair et al., 2005). Finally, employing our diffusion/active-transport/binding model (Maza et al., 2019), and considering the measured diffusivities of soluble proteins in the various rod compartments (Calvert et al., 2006, 2010; Najafi et al., 2012), we have predicted that the distribution of Arr1 in rods where the OS binding sinks had affinities corresponding to non-phosphorylated light-activated rhodopsin were nearly indistinguishable from that of rods with OS binding sinks with affinities corresponding to phosphorylated light-activated rhodopsin.

The notion that light-dependent Arr1 transport to the OS is independent of energy remains controversial, however. A more recent study in Xenopus and mouse showed that Arr1 transport to the OS in light-adapted rods was absent upon ATP depletion with potassium cyanide $(\mathrm{KCN})$, and was restored with KCN washout and ATP supplementation (Orisme et al., 2010). The study further suggested that light-stimulated Arr1 transport is triggered by an ATP-dependent, PLC activated mechanism, perhaps mediated by D2 dopamine receptors. It is proposed that this pathway releases Arr1 from the IS by an unspecified mechanism and allows it to diffuse to the OS, where it is then retained by binding to light-activated rhodopsin. Together, these studies strongly support the diffusion to binding sink model for Arr1 transport to the OS of lightadapted rods, where the initial transport may require some form of release from the IS compartment. Interestingly, Strissel et al. observed that light stimulated Arr1 transport occurs at a threshold that activated $\sim 3 \%$ of rhodopsins (Strissel et al., 2006). At light levels near this threshold the amount of Arr1 that transported to the OS was ten-fold higher than the number of rhodopsins activated by light, which is referred to as super-stoichiometric Arr1 transport, through an unidentified mechanism that requires phototransduction. It would be interesting to explore if the PLC-dependent mechanism might underlie this super-stoichiometric movement.

Several theories have been posited to explain the disproportionately IS biased distribution of Arr1 in darkadapted rods, including a diffusion barrier at the base of the $\mathrm{CC}$ and tethering to IS structures by multiple binding partners, including NSF, enolase-1, and tubulin (Nair et al., 2004; Huang et al., 2010; Smith et al., 2011). However, studies of the dynamics of the soluble proteins EGFP and PAGFP have shown that there is no significant barrier impeding diffusion of soluble proteins up to $\sim 80 \mathrm{kDa}$ through the CC (Calvert et al., 2010; Najafi et al., 2012), and none of the Arr1 IS binding partners have sufficient concentration and localization to account for Arr1's distribution in the dark. This analysis led us to explore other mechanisms. We reasoned that the distribution of soluble proteins within cells will be governed by the available aqueous cytoplasmic spaces and interactions with binding partners (Peet et al., 2004). At first glance this appears to be a simple idea, however, the cytoplasm is crowded, and the available aqueous spaces are distributed among a heterogeneous patchwork of cytoplasmic structures. Highly organized organelles, like the lamellae of the ER and Golgi membranes, are interspersed with more open spaces. The meshwork of cytoskeletal components introduces sieves of variable mesh size. Together these structural features of the cytoplasm lead to partitioning of solutes into different cytoplasmic domains of cultured cells based on size (Luby-Phelps et al., 1986; Minton, 1992, 1997; Zimmerman and Minton, 1993; Janson et al., 1996; Zhou et al., 2008). In theory, partitioning of soluble molecules based on accessible cytoplasmic spaces may be a means of regulating cellular activities. However, quantifying that potential impact is difficult for most cells due to the spatial resolution limitations of light microscopes.

Amphibian photoreceptors provided a model cell where the impact of soluble protein partitioning by heterogeneous cytoplasmic spaces could be quantified (Figure 8) (Najafi et al., 2012). The large size of amphibian rods and the unique structure of photoreceptor OSs, with highly uniform spacing and close juxtaposition of the discs ( $\sim 12 \mathrm{~nm}$ inter-disc spacing), allows quantification of the distributions of soluble molecules between the OS and the much less structurally constrained IS/cell body (Figure 8A). The ratio of molecules in the OS to that in the IS falls steeply, from $\sim 0.85-\sim 0.15$, as the size of molecules increase from $600 \mathrm{Da}$ to $\sim 81 \mathrm{kDa}$ (Figure 8B). Analysis of the size dependent distribution of molecules in the Xenopus rods agrees well with a model whereby the accessible volume within the OS declines much more steeply than the accessible volume in the IS due to steric interactions limiting the approach of the molecules to membranes and other surfaces (Figure 8C).

The steric volume exclusion effect operates in all cell compartments. Differences in the geometry of the compartments and the size of soluble proteins underlie the differential partitioning effect. To illustrate this, consider two interconnected cuboid compartments with identical geometrical volumes (Figure 8C). The volume accessible to the center of mass of a spherical protein is lower in the rectangular compartment than in the cubical. Moreover, the relationship between the accessible volume and the size of molecules falls more steeply 


\section{A}

Calcein

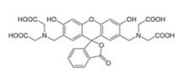

1x EGFP

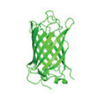

2x EGFP

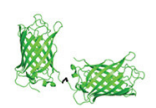

3x EGFP
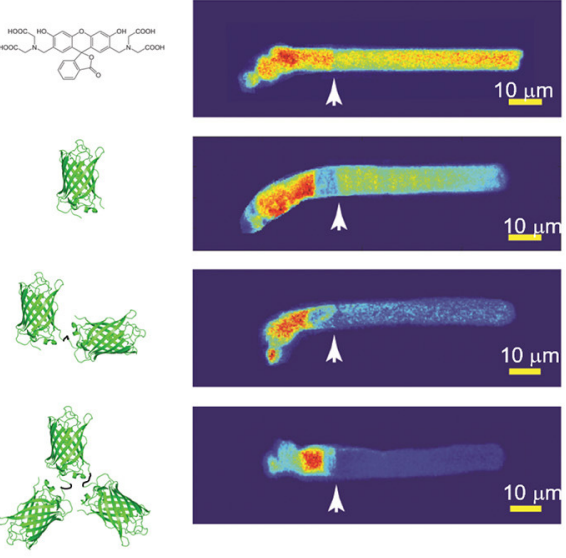

\section{B}

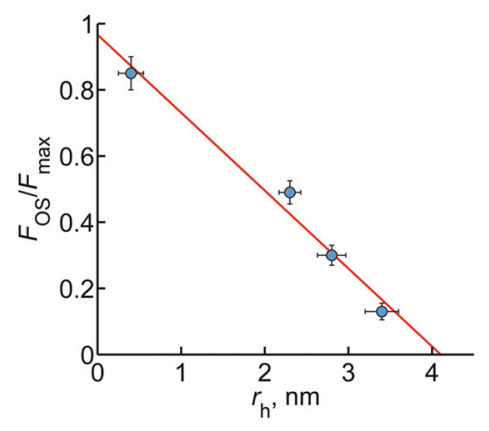

D

C
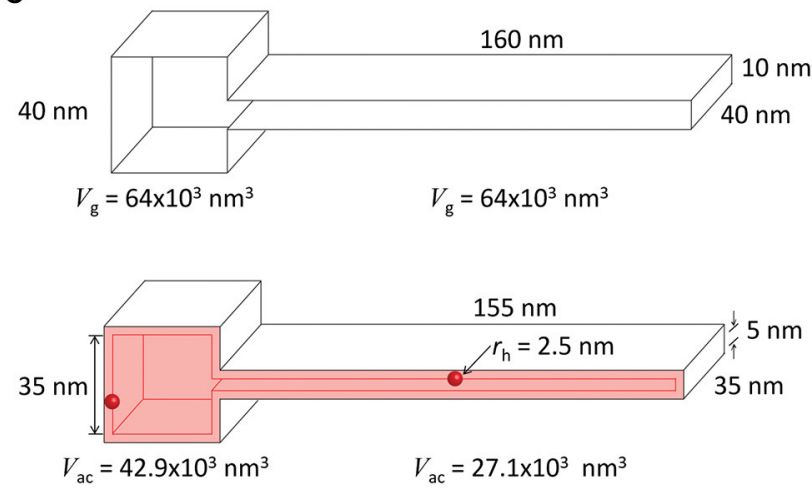

$V_{\mathrm{ac}}=27.1 \times 10^{3} \mathrm{~nm}^{3}$

E

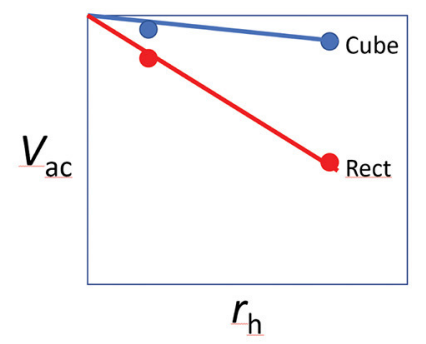

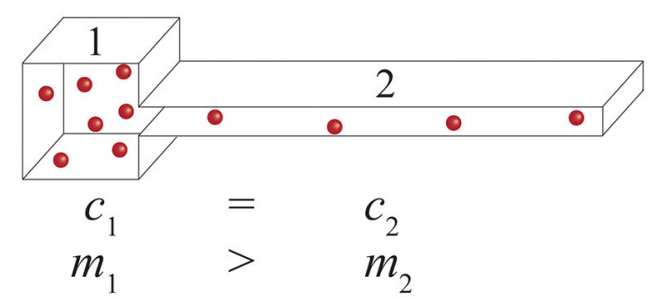

FIGURE 8 | Steric volume exclusion and the compartmentalization of soluble proteins in photoreceptors. (A) The distribution of soluble molecules in Xenopus rods depends on the size of the molecule. Note that the conformation of the EGFP dimers and tetramer shown are only one of many possible. (B) The relationship of the ratio of the OS fluorescence to the maximum IS fluorescence scaled inversely and linearly with the estimated average hydrated radius of the molecules. This phenomenon can be explained by the asymmetrical reduction in the available aqueous volume of the differently shaped compartments caused by steric volume exclusion (i.e., loss of volume available to the center of mass of the molecule). (C) For example, two interconnected boxes have the same geometric volume $\left(V_{\mathrm{g}}\right)$, but vastly different shapes. Introducing a spherical molecule reduces the geometry of both compartments, and thus the volumes accessible $\left(V_{\text {ac }}\right)$ to their centers of mass of the molecule. This reduction is larger for the rectangular compartment. (D) As the hydrated radius $\left(r_{\mathrm{h}}\right)$ of the molecules increase, the reduction in $V_{\text {ac }}$ falls more steeply for the rectangular compartment. (E) Since soluble molecules will equilibrate to equalize their concentrations (C) everywhere, the shape asymmetry will cause partitioning of the soluble molecules into the cubical compartment, where the total mass $(m)$ will be higher. (A,B) modified from Najafi et al. (2012).

in the rectangular compartment (Figure 8D). This difference in accessible volume means that the effective concentration of a given number of molecules in these two compartments will be higher in the rectangular compartment. This difference in effective concentration drives partitioning of the molecules into the cube shaped compartment. Thus, although the effective concentration of the soluble molecules will be the same in both compartments, the number of molecules will be lower in the rectangular compartment. In many signaling scenarios, it is the number of molecules that is most important. For instance, in photoreceptors the number of soluble Arr1 molecules in the inter-discal spaces dictate how quickly a light activated rhodopsin molecule is quenched.

The distribution by accessible volumes model predicts that Arr1 will be fivefold enriched in the IS relative to the OS (Najafi et al., 2012), somewhat less than the $\sim 13$-fold enrichment 
observed in dark-adapted rods. However, in vitro studies have shown that Arr1 can form dimers and tetramers (Granzin et al., 1998; Hirsch et al., 1999; Schubert et al., 1999; Shilton et al., 2002; Imamoto et al., 2003; Hanson et al., 2007, 2008; Kim et al., 2011), and the millimolar concentration of Arr1 in rods predicts the majority of Arr1 is in the dimer $(\sim 96 \mathrm{kDa})$ or tetramer $(\sim 192$ $\mathrm{kDa}$ ) forms. If the physiological form of Arr1 in dark-adapted rods is indeed dimer or tetramer, the dark-adapted partitioning of Arr1 can be explained simply by partitioning into the IS resulting from the heterogeneity of OS and IS structures and the steric volume exclusion effect. The distribution by steric volume exclusion-dependent partitioning between the OS and the rest of the cell is appealing for a number of reasons. First, it explains why Arr1 is found uniformly filling the entire non-OS compartments of dark-adapted rods, from the myoid region to the presynaptic spherule. Second, it overcomes the problem that the proposed non-rhodopsin Arr1 binding partners are not expressed to levels even nearly approaching that of Arr1. Third, although it has been proposed that Arr1 binds to microtubules (Nair et al., 2005; Orisme et al., 2010) and the BBSome protein BBS5 (Orisme et al., 2010), the sheer mass of Arr1 binding would appear to substantially inhibit other vital microtubule and BBS5 functions, including delivery of tubulin and other cargoes by IFT. Finally, distribution by steric volume exclusion offers the possibility of straightforward regulation of Arr1 distribution either through regulation of self-association or regulating the disc spacing in the OSs, which appear to elongate in response to light in the intact eye (Zhang et al., 2017).

\section{CONCLUDING REMARKS}

Photoreceptor OSs are modified primary cilia with highly elaborated membrane systems that serve to efficiently capture photons and transduce them into electrical signals. To support this role, proteins involved in phototransduction and maintenance of the OS structure must be transported to the

\section{REFERENCES}

Abd-El-Barr, M. M., Sykoudis, K., Andrabi, S., Eichers, E. R., Pennesi, M. E., Tan, P. L., et al. (2007). Impaired photoreceptor protein transport and synaptic transmission in a mouse model of Bardet-Biedl syndrome. Vision Res. 47, 3394-3407. doi: 10.1016/j.visres.2007.09.016

Albert, A. D., and Boesze-Battaglia, K. (2005). The role of cholesterol in rod outer segment membranes. Progress Lipid Res. 44, 99-124. doi: 10.1016/j.plipres.2005.02.001

Alpadi, K., Magupalli, V. G., Käppel, S., Köblitz, L., Schwarz, K., Seigel, G. M., et al. (2008). RIBEYE recruits Munc119, a mammalian ortholog of the Caenorhabditis elegans protein unc119, to synaptic ribbons of photoreceptor synapses. J. Biol. Chem. 283, 26461-26467. doi: 10.1074/jbc.M801625200

Ames, J. B., Porumb, T., Tanaka, T., Ikura, M., and Stryer, L. (1995a). Aminoterminal myristoylation induces cooperative calcium binding to recoverin. J. Biol. Chem. 270, 4526-4533. doi: 10.1074/jbc.270.9.4526

Ames, J. B., Tanaka, T., Ikura, M., and Stryer, L. (1995b). Nuclear magnetic resonance evidence for $\mathrm{Ca}(2+)$-induced extrusion of the myristoyl group of recoverin. J. Biol. Chem. 270, 30909-30913. doi: 10.1074/jbc.270.52.30909

Anant, J. S., Ong, O. C., Xie, H. Y., Clarke, S., O'Brien, P. J., and Fung, B. K. (1992). In vivo differential prenylation of retinal cyclic
OS, an especially daunting problem for photoreceptors because of the sheer mass of protein and membranes that are required for daily renewal of $10 \%$ of the OS. Over the last decade and a half, significant advances in our understanding of the molecular players involved in photoreceptor OS genesis and protein transport have been made due to a refreshed examination of this problem using focused mouse genetic models, advanced proteomics and the development of sophisticated approaches to high resolution imaging of the $\mathrm{CC} /$ photoreceptor transition zone, including cryo-EM tomography and super-resolution fluorescence microscopy. Recent advances in live cell imaging in photoreceptors, primary cilia and flagella, however, have begun to challenge previous notions of the mechanisms underlying ciliary protein transport, ciliary construction and maintenance in health and disease. We are just at the beginning-further development of high spatial and temporal resolution approaches to quantifying the dynamics of protein and membrane transport in living photoreceptors and other cilia represents a critical area for advancing the field.

\section{AUTHOR CONTRIBUTIONS}

$\mathrm{CB}$ and HM: Researched, wrote draft, and edited manuscript. PC: Proposed review article, researched, wrote draft, edited manuscript, and generated figures. All authors contributed to the article and approved the submitted version.

\section{FUNDING}

This work was supported by grants from the National Eye Institute, R01EY018421 (PC) and R01 EY028303 (PC). PC was recipient of a Stein Innovation Award from Research to Prevent Blindness Inc. The Department of Ophthalmology and Visual Sciences is supported by an unrestricted grant from Research to Prevent Blindness Inc and by LionsMD-Y.
GMP phosphodiesterase catalytic subunits. J. Biol. Chem. 267, 687-690. doi: 10.1016/S0021-9258(18)48336-6

Anderson, D. H., Fisher, S. K., and Steinberg, R. H. (1978). Mammalian cones: disc shedding, phagocytosis, and renewal. Invest. Ophthal. Visual Sci. 17, 117-133.

Ashmore, J. F., and Falk, G. (1977). Dark noise in retinal bipolar cells and stability of rhodopsin in rods. Nature 270, 69-71. doi: 10.1038/270069a0

Avasthi, P., Watt, C. B., Williams, D. S., Le, Y. Z., Li, S., Chen, C. K., et al. (2009). Trafficking of membrane proteins to cone but not rod outer segments is dependent on heterotrimeric kinesin-II. J. Neurosci. 29, 14287-14298. doi: 10.1523/JNEUROSCI.3976-09.2009

Awata, J., Takada, S., Standley, C., Lechtreck, K. F., Bellve, K. D., Pazour, G. J., et al. (2014). NPHP4 controls ciliary trafficking of membrane proteins and large soluble proteins at the transition zone. J. Cell Sci. 127, 4714-4727. doi: $10.1242 /$ jcs. 155275

Badgandi, H. B., Hwang, S.-H, Shimada, I. S., Loriot, E., and Mukhopadhyay, S. (2017). Tubby family proteins are adapters for ciliary trafficking of integral membrane proteins. J. Cell Biol. 216, 743-760. doi: 10.1083/jcb.201607095

Baker, S. A., Haeri, M., Yoo, P., Gospe, S. M. I. I. I., Skiba, N. P., Knox, B. E., et al. (2008). The outer segment serves as a default destination for the trafficking of membrane proteins in photoreceptors. J. Cell Biol. 183, 485-498. doi: $10.1083 /$ jcb. 200806009 
Bales, K. L., Bentley, M. R., Croyle, M. J., Kesterson, R. A., Yoder, B. K., and Gross, A. K. (2020). BBSome component BBS5 is required for cone photoreceptor protein trafficking and outer segment maintenance. Invest. Ophthalmol. Vis. Sci. 61:17. doi: 10.1167/iovs.61.10.17

Barnes, S. N. (1971). Fine structure of the photoreceptor and cerebral ganglion of the tadpole larva of Amaroucium constellatum (Verril) (subphylum: Urochordata; class: Ascidiacea). Z. Zellforsch Mikrosk Anat. 117, 1-16. doi: 10.1007/BF00331097

Baylor, D. A., Lamb, T. D., and Yau, K. W. (1979). The membrane current of single rod outer segments. J. Physiol. 288, 589-611. doi: 10.1016/0042-6989(79)90077-4

Benmerah, A. (2013). The ciliary pocket. Curr. Opin. Cell Biol. 25, 78-84. doi: 10.1016/j.ceb.2012.10.011

Berbari, N. F., Lewis, J. S., Bishop, G. A., Askwith, C. C., and Mykytyn, K. (2008). Bardet-Biedl syndrome proteins are required for the localization of $\mathrm{G}$ proteincoupled receptors to primary cilia. Proc. Natl. Acad. Sci. U.S.A. 105, 4242-4246. doi: 10.1073/pnas.0711027105

Besharse, J. C. (1986). "Photosensitive membrane Turnover: differentiated membrane domains and cell-cell interaction," in The Retina: A Model for Cell Biological Studies, eds R. Adler and D. Farber (Orlando, FL: New York Academic Press), 297-352. doi: 10.1016/B978-0-12-044275-1.50014-4

Besharse, J. C., Hollyfield, J. G., and Rayborn, M. E. (1977). Turnover of rod photoreceptor outer segments. II. Membrane addition and loss in relationship to light. J. Cell Biol. 75, 507-527. doi: 10.1083/jcb.75.2.507

Bhamidipati, A., Lewis, S. A., and Cowan, N. J. (2000). ADP ribosylation factorlike protein 2 (Arl2) regulates the interaction of tubulin-folding cofactor $\mathrm{D}$ with native tubulin. J Cell Biol. 149, 1087-1096. doi: 10.1083/jcb.149.5.1087

Bhowmick, R., Li, M., Sun, J., Baker, S. A., Insinna, C., and Besharse, J. C. (2009). Photoreceptor IFT complexes containing chaperones, guanylyl cyclase 1 and rhodopsin. Traffic 10, 648-663. doi: 10.1111/j.1600-0854.2009.00896.x

Bielas, S. L., Silhavy, J. L., Brancati, F., Kisseleva, M. V., Al-Gazali, L., Sztriha, L., et al. (2009). Mutations in INPP5E, encoding inositol polyphosphate-5phosphatase E, link phosphatidyl inositol signaling to the ciliopathies. Nat. Genet. 41, 1032-1036. doi: 10.1038/ng.423

Boubakri, M., Chaya, T., Hirata, H., Kajimura, N., Kuwahara, R., Ueno, A., et al. (2016). Loss of ift122, a retrograde intraflagellar transport (IFT) complex component, leads to slow, progressive photoreceptor degeneration due to inefficient opsin transport. J. Biol. Chem. 291, 24465-24474. doi: 10.1074/jbc.M116.738658

Breslow, D. K., Koslover, E. F., Seydel, F., Spakowitz, A. J., and Nachury, M. V. (2013). An in vitro assay for entry into cilia reveals unique properties of the soluble diffusion barrier. J. Cell Biol. 203, 129-147. doi: 10.1083/jcb.201212024

Bretscher, A., Edwards, K., and Fehon, R. G. (2002). ERM proteins and merlin: integrators at the cell cortex. Nat. Rev. Mol. Cell Biol. 3, 586-599. doi: $10.1038 / \mathrm{nrm} 882$

Broekhuis, J. R., Verhey, K. J., and Jansen, G. (2014). Regulation of cilium length and intraflagellar transport by the RCK-Kinases ICK and MOK in renal epithelial cells. PLoS ONE. 9:e108470. doi: 10.1371/journal.pone.0108470

Broekhuyse, R. M., Tolhuizen, E. F., Janssen, A. P., and Winkens, H. J. (1985). Light induced shift and binding of S-antigen in retinal rods. Curr. Eye Res. 4, 613-618. doi: 10.3109/02713688508999993

Brooks, C., Murphy, J., Belcastro, M., Heller, D., Kolandaivelu, S., Kisselev, O., et al. (2018). Farnesylation of the transducin g protein gamma subunit is a prerequisite for its ciliary targeting in rod photoreceptors. Front. Mol. Neurosci. 11:16. doi: 10.3389/fnmol.2018.00016

Brown, B. M., Carlson, B. L., Zhu, X., Lolley, R. N., and Craft, C. M. (2002). Light-driven translocation of the protein phosphatase $2 \mathrm{~A}$ complex regulates light/dark dephosphorylation of phosducin and rhodopsin. Biochemistry 41, 13526-13538. doi: 10.1021/bi0204490

Brown, P. K., Gibbons, I. R., and Wald, G. (1963). The visual cells and visual pigment of the mudpuppy, necturus. J. Cell Biol. 19, 79-106. doi: $10.1083 /$ jcb.19.1.79

Bujakowska, K. M., Zhang, Q., Siemiatkowska, A. M., Liu, Q., Place, E., Falk, M. J., et al. (2015). Mutations in IFT172 cause isolated retinal degeneration and Bardet-Biedl syndrome. Hum. Mol. Genet. 24, 230-242. doi: $10.1093 / \mathrm{hmg} / \mathrm{ddu} 441$

Burgoyne, T., Meschede, I. P., Burden, J. J., Bailly, M., Seabra, M. C., and Futter, C. E. (2015). Rod disc renewal occurs by evagination of the ciliary plasma membrane that makes cadherin-based contacts with the inner segment. Proc. Natl. Acad. Sci. U.S.A. 112, 15922-15927. doi: 10.1073/pnas.15092 85113

Calvert, P. D., Klenchin, V. A., and Bownds, M. D. (1995). Rhodopsin kinase inhibition by recoverin. Function of recoverin myristoylation. J. Biol. Chem. 270, 24127-24129. doi: 10.1074/jbc.270.41.24127

Calvert, P. D., Schiesser, W. E., and Pugh, E. N. Jr. (2010). Diffusion of a soluble protein, photoactivatable GFP, through a sensory cilium. J. Gen. Physiology. 135, 173-196. doi: 10.1085/jgp.200910322

Calvert, P. D., Strissel, K. J., Schiesser, W. E., Pugh, E. N. Jr., and Arshavsky, V. Y. (2006). Light-driven translocation of signaling proteins in vertebrate photoreceptors. Trends Cell Biol. 16, 560-568. doi: 10.1016/j.tcb.2006.09.001

Cantagrel, V., Silhavy, J. L., Bielas, S. L., Swistun, D., Marsh, S. E., Bertrand, J. Y., et al. (2008). Mutations in the cilia gene ARL13B lead to the classical form of Joubert syndrome. Am. J. Hum. Genet. 83, 170-179. doi: 10.1016/j.ajhg.2008.06.023

Cen, O., Gorska, M. M., Stafford, S. J., Sur, S., and Alam, R. (2003). Identification of UNC119 as a novel activator of SRC-type tyrosine kinases. J. Biol. Chem. 278, 8837-8845. doi: 10.1074/jbc.M208261200

Chadha, A., Volland, S., Baliaouri, N. V., Tran, E. M., and Williams, D. S. (2019). The route of the visual receptor rhodopsin along the cilium. J. Cell Sci. 132:jcs229526. doi: 10.1242/jcs.229526

Chaya, T., Tsutsumi, R., Varner, L. R., Maeda, Y., Yoshida, S., and Furukawa, T. (2019). Cul3-Klhl18 ubiquitin ligase modulates rod transducin translocation during light-dark adaptation. EMBO J. 38:e101409. doi: 10.15252/embj.2018101409

Chen, C. K., Inglese, J., Lefkowitz, R. J., and Hurley, J. B. (1995). Ca(2+)dependent interaction of recoverin with rhodopsin kinase. J. Biol. Chem. 270, 18060-18066. doi: 10.1074/jbc.270.30.18060

Chuang, J.-Z., Zhao, Y., and and, C.-,Sung, H. (2007). SARA-regulated vesicular targeting underlies formation of the light-sensing organelle in mammalian rods. Cell 130, 535-547. doi: 10.1016/j.cell.2007.06.030

Coleman, D. L., and Eicher, E. M. (1990). Fat (fat) and tubby (tub): two autosomal recessive mutations causing obesity syndromes in the mouse. J. Hered. 81, 424-427. doi: 10.1093/oxfordjournals.jhered.a111019

Conley, S. M., Al-Ubaidi, M. R., and Naash, M. I. (2019a). The role of the Prph2 Cterminus in outer segment morphogenesis. Adv. Exp. Med. Biol. 1185, 495-499. doi: 10.1007/978-3-030-27378-1_81

Conley, S. M., Stuck, M. W., Watson, J. N., Zulliger, R., Burnett, J. L., and Naash, M. I. (2019b). Prph2 initiates outer segment morphogenesis but maturation requires Prph2/Rom1 oligomerization. Hum. Mol. Genet. 28, 459-475. doi: 10.1093/hmg/ddy359

Corral-Serrano, J. C., Lamers, I. J., van Reeuwijk, J., Duijkers, L., Hoogendoorn, A. D., Yildirim, A., et al. (2020). PCARE and WASF3 regulate ciliary Factin assembly that is required for the initiation of photoreceptor outer segment disk formation. Proc. Natl. Acad. Sci. U.S.A. 117, 9922-9931. doi: 10.1073/pnas.1903125117

Country, M. W. (2017). Retinal metabolism: a comparative look at energetics in the retina. Brain Res. 1672, 50-57. doi: 10.1016/j.brainres.2017.07.025

Craft, J. M., Harris, J. A., Hyman, S., Kner, P., and Lechtreck, K. F. (2015). Tubulin transport by IFT is upregulated during ciliary growth by a cilium-autonomous mechanism. J. Cell Biol. 208, 223-237. doi: 10.1083/jcb.201409036

Dartnall, H. J. A. (ed.). (1972). "Photosensitivity," in Photochemistry of Vision. Handbook of Sensory Physiology, Vol. 7/1 (Berlin; Heidelberg: Springer), 122 145. doi: 10.1007/978-3-642-65066-6_4

Datta, P., Allamargot, C., Hudson, J. S., Andersen, E. K., Bhattarai, S., Drack, A. V., et al. (2015). Accumulation of non-outer segment proteins in the outer segment underlies photoreceptor degeneration in Bardet-Biedl syndrome. Proc. Natl. Acad. Sci. U.S.A. 112, E4400-E4409. doi: 10.1073/pnas.1510111112

Davidson, A. E., Schwarz, N., Zelinger, L., Stern-Schneider, G., Shoemark, A., Spitzbarth, B., et al. (2013). Mutations in ARL2BP, encoding ADP-ribosylationfactor-like 2 binding protein, cause autosomal-recessive retinitis pigmentosa. Am J. Hum. Genet. 93, 321-329. doi: 10.1016/j.ajhg.2013.06.003

Davis, R. E., Swiderski, R. E., Rahmouni, K., Nishimura, D. Y., Mullins, R. F., Agassandian, K., et al. (2007). A knockin mouse model of the BardetBiedl syndrome 1 M390R mutation has cilia defects, ventriculomegaly, retinopathy, and obesity. Proc. Natl. Acad. Sci. U.S.A. 104, 19422-19427. doi: $10.1073 /$ pnas.0708571104 
De Matteis, M., Godi, A., and Corda, D. (2002). Phosphoinositides and the golgi complex. Curr. Opin. Cell Biol. 14, 434-447. doi: 10.1016/S0955-0674(02)00357-5

Deretic, D., Lorentzen, E., and Fresquez, T. (2019). The ins and outs of the Arf4-based ciliary membrane-targeting complex. Small GTPases 12, 1-12. doi: 10.1080/21541248.2019.1616355

Deretic, D., and Mazelova, J. (2009). Assay for in vitro budding of ciliarytargeted rhodopsin transport carriers. Methods Cell Biol. 94, 241-257. doi: 10.1016/S0091-679X(08)94012-7

Deretic, D., and Papermaster, D. S. (1991). Polarized sorting of rhodopsin on post-Golgi membranes in frog retinal photoreceptor cells. J. Cell Biol. 113, 1281-1293. doi: 10.1083/jcb.113.6.1281

Deretic, D., Schmerl, S., Hargrave, P. A., Arendt, A., and McDowell, J. H. (1998). Regulation of sorting and post-Golgi trafficking of rhodopsin by its Cterminal sequence QVS(A)PA. Proc. Natl. Acad. Sci. U.S.A. 95, 10620-10625. doi: $10.1073 /$ pnas.95.18.10620

Deretic, D., Traverso, V., Parkins, N., Jackson, F., E. B., Rodriguez de Turco, and Ransom, N. (2004). Phosphoinositides, ezrin/moesin, and racl regulate fusion of rhodopsin transport carriers in retinal photoreceptors. Mol. Biol. Cell. 15, 359-370. doi: 10.1091/mbc.e03-04-0203

Deretic, D., and Wang, J. (2012). Molecular assemblies that control rhodopsin transport to the cilia. Vision Res. 75, 5-10. doi: 10.1016/j.visres.2012.07.015

Deretic, D., Williams, A. H., Ransom, N., Morel, V., Hargrave, P. A., and Arendt, A. (2005). Rhodopsin C terminus, the site of mutations causing retinal disease, regulates trafficking by binding to ADP-ribosylation factor 4 (ARF4). Proc. Natl. Acad. Sci. U.S.A. 102, 3301-3306. doi: 10.1073/pnas.0500095102

Desai, P. B., Stuck, M. W., Lv, B., and Pazour, G. J. (2020). Ubiquitin links smoothened to intraflagellar transport to regulate Hedgehog signaling. J. Cell Biol. 219:e201912104. doi: 10.1083/jcb.201912104

Dharmat, R., Eblimit, A., Robichaux, M. A., Zhang, Z., T.-,Nguyen, M. T., Jung, S. Y., et al. (2018). SPATA7 maintains a novel photoreceptorspecific zone in the distal connecting cilium. J. Cell Biol. 217, 2851-2865. doi: $10.1083 /$ jcb.201712117

Dilan, T. L., Moye, A. R., Salido, E. M., Saravanan, T., Kolandaivelu, S., A., et al. (2019). ARL13B, a joubert syndrome-associated protein, is critical for retinogenesis and elaboration of mouse photoreceptor outer segments. J. Neurosci. 39, 1347-1364. doi: 10.1523/JNEUROSCI.1761-18.2018

Dilan, T. L., Singh, R. K., Saravanan, T., Moye, A., A., Goldberg, F. X., et al. (2018). Bardet-Biedl syndrome-8 (BBS8) protein is crucial for the development of outer segments in photoreceptor neurons. Hum. Mol. Genet. 27, 283-294. doi: $10.1093 / \mathrm{hmg} / \mathrm{ddx} 399$

Ding, J.-D., Salinas, R. Y., and Arshavsky, V. Y. (2015). Discs of mammalian rod photoreceptors form through the membrane evagination mechanism. J. Cell Biol. 211, 495-502. doi: 10.1083/jcb.201508093

Dizhoor, A. M., Ericsson, L. H., Johnson, R. S., Kumar, S., Olshevskaya, E., Zozulya, S., et al. (1992). The NH2 terminus of retinal recoverin is acylated by a small family of fatty acids. J. Biol. Chem. 267, 16033-16036. doi: 10.1016/S0021-9258(18)41959-X

Domire, J. S., Green, J. A., Lee, K. G., Johnson, A. D., Askwith, C. C., and Mykytyn, K. (2011). Dopamine receptor 1 localizes to neuronal cilia in a dynamic process that requires the Bardet-Biedl syndrome proteins. Cell. Mol. Life Sci. 68, 2951-2960. doi: 10.1007/s00018-010-0603-4

Donaldson, J. G. (2005). Arfs, phosphoinositides and membrane traffic. Biochem. Soc. Trans. 33, 1276-1278. doi: 10.1042/BST0331276

Eakin, R. M., and Kuda, A. (1971). Ultrastructure of sensory receptors in Ascidian tadpoles. Z Zellforsch Mikrosk Anat. 112, 287-312. doi: 10.1007/BF02584045

Eckmiller, M. S. (1996). Renewal of the ciliary axoneme in cone outer segments of the retina of Xenopus laevis. Cell Tissue Res. 285, 165-169. doi: $10.1007 / \mathrm{s} 004410050632$

Enoch, J. M. (1980). Vertebrate receptor optics and orientation. Documenta ophthalmologica. Adv. Ophthal. 48, 373-388. doi: 10.1007/BF00141466

Evans, R. J., Schwarz, N., Nagel-Wolfrum, K., Wolfrum, U., Hardcastle, A. J., and Cheetham, M. E. (2010). The retinitis pigmentosa protein RP2 links pericentriolar vesicle transport between the Golgi and the primary cilium. Hum. Mol. Genet. 19, 1358-1367. doi: 10.1093/hmg/ddq012

Fetter, R. D., and Corless, J. M. (1987). Morphological components associated with frog cone outer segment disc margins. Invest. Ophthal. Vis. Sci. 28, 646-657.
Finkelstein, S., Gospe, S. M. 3rd, Schuhmann, K., Shevchenko, A., Arshavsky, V. Y., and Lobanova, E. S. (2020). Phosphoinositide Profile of the Mouse Retina. Cells 9:1417. doi: 10.3390/cells9061417

Fliesler, A. J., and Anderson, R. E. (1983). Chemistry and metabolism of lipids in the vertebrate retina. Progress Lipid Res. 22, 79-131. doi: 10.1016/0163-7827(83)90004-8

Fliesler, S. J., Rayborn, M. E., and Hollyfield, J. G. (1985). Membrane morphogenesis in retinal rod outer segments: inhibition by tunicamycin. J. Cell Biol. 100, 574-587. doi: 10.1083/jcb.100.2.574

Follit, J. A., Tuft, R. A., Fogarty, K. E., and Pazour, G. J. (2006). The intraflagellar transport protein IFT20 is associated with the golgi complex and is required for cilia assembly. Mol. Biol. Cell. 17, 3781-3792. doi: 10.1091/mbc.e06-02-0133

Fukada, Y., Takao, T., Ohguro, H., Yoshizawa, T., Akino, T., and Shimonishi, Y. (1990). Farnesylated gamma-subunit of photoreceptor $\mathrm{G}$ protein indispensable for GTP-binding. Nature 346, 658-660. doi: 10.1038/346658a0

Garcia, G. III, Raleigh, D. R., and Reiter, J. F. (2018). How the ciliary membrane is organized inside-out to communicate outside-In. Curr Biol. 28, R421-R434. doi: 10.1016/j.cub.2018.03.010

Gaudet, R., Bohm, A., and Sigler, P. B. (1996). Crystal structure at 2.4 angstroms resolution of the complex of transducin betagamma and its regulator, phosducin. Cell 87, 577-588. doi: 10.1016/S0092-8674(00)81376-8

Gehring, W. J. (2004). Historical perspective on the development and evolution of eyes and photoreceptors. Int. J. Dev. Biol. 48, 707-717. doi: 10.1387/ijdb.041900wg

Geneva, I. I., Tan, H. Y., and Calvert, P. D. (2017). Untangling ciliary access and enrichment of two rhodopsin-like receptors using quantitative fluorescence microscopy reveals cell-specific sorting pathways. Mol. Biol. Cell. 28, 554-566. doi: 10.1091/mbc.e16-07-0549

Gilliam, J. C., Chang, J. T., Sandoval, I. M., Zhang, Y., Li, T., Pittler, S. J., et al. (2012). Three-dimensional architecture of the rod sensory cilium and its disruption in retinal neurodegeneration. Cell 151, 1029-1041. doi: 10.1016/j.cell.2012.10.038

Godi, A., Di Campli, A., Konstantakopoulos, A., Di Tullio, G., Alessi, D. R., Kular, G. S., et al. (2004). FAPPs control Golgi-to-cell-surface membrane traffic by binding to ARF and PtdIns(4)P. Nat. Cell Biol. 6, 393-404. doi: $10.1038 /$ ncb1119

Gonçalves, J., and Pelletier, L. (2017). The ciliary transition zone: finding the pieces and assembling the gate. Mol. Cells. 40:243. doi: 10.14348/molcells.2017.0054

Gotthardt, K., Lokaj, M., Koerner, C., Falk, N., Gießl, A., and Wittinghofer, A. (2015). A G-protein activation cascade from Arl13B to Arl3 and implications for ciliary targeting of lipidated proteins. eLife 4:e11859. doi: 10.7554/eLife.11859

Granzin, J., Wilden, U., Choe, H. W., Labahn, J., Krafft, B., and Buldt, G. (1998). $\mathrm{X}$-ray crystal structure of arrestin from bovine rod outer segments. Nature 391, 918-921. doi: 10.1038/36147

Grayson, C., Bartolini, F., Chapple, J. P., Willison, K. R., Bhamidipati, A., Lewis, S. A., et al. (2002). Localization in the human retina of the X-linked retinitis pigmentosa protein RP2, its homologue cofactor C and the RP2 interacting protein Arl3. Hum. Mol. Genet. 11, 3065-3074. doi: 10.1093/hmg/11. 24.3065

Gu, S., Lennon, A., Li, Y., Lorenz, B., Fossarello, M., North, M., et al. (1998). Tubbylike protein-1 mutations in autosomal recessive retinitis pigmentosa. Lancet 351, 1103-1104. doi: 10.1016/S0140-6736(05)79384-3

Haeseleer, F. (2008). Interaction and colocalization of CaBP4 and Unc119 (MRG4) in photoreceptors. Invest. Ophthal. Vis. Sci. 49, 2366-2375. doi: 10.1167/iovs.07-1166

Hagstrom, S. A., Duyao, M., North, M. A., and Li, T. (1999). Retinal Degeneration in tulp1 -/- Mice: vesicular accumulation in the Interphotoreceptor Matrix. Invest. Ophthal. Vis. Sci. 40, 2795-2802.

Hanke-Gogokhia, C., Wu, Z., Gerstner, C. D., Frederick, J. M., Zhang, H., and Baehr, W. (2016). Arf-like protein 3 (ARL3) regulates protein trafficking and ciliogenesis in mouse photoreceptors. J. Biol. Chem. 291, 7142-7155. doi: 10.1074/jbc.M115.710954

Hanke-Gogokhia, C., Wu, Z., Sharif, A., Yazigi, H., Frederick, J. M., and Baehr, W. (2017). The guanine nucleotide exchange factor Arf-like protein 13b is essential for assembly of the mouse photoreceptor transition zone and outer segment. J. Biol. Chem. 292, 21442-21456. doi: 10.1074/jbc.RA117.000141 
Hanson, S. M., Dawson, E. S., Francis, D. J., Van Eps, N., Klug, C. S., Hubbell, W. L., et al. (2008). A model for the solution structure of the rod arrestin tetramer. Structure 16, 924-934. doi: 10.1016/j.str.2008.03.006

Hanson, S. M., Van Eps, N., Francis, D. J., Altenbach, C., Vishnivetskiy, S. A., Arshavsky, V. Y., et al. (2007). Structure and function of the visual arrestin oligomer. EMBO J. 26, 1726-1736. doi: 10.1038/sj.emboj.7601614

Hecht, S., Shlaer, S., and Pirenne, M. H. (1942). Energy, quanta, and vision. J. Gen. Physiol. 25, 819-840. doi: 10.1085/jgp.25.6.819

Hernandez-Hernandez, V., and Jenkins, D. (2015). Advances in the understanding of the BBSome complex structure and function. Res. Rep. Biol. 6, 191-201. doi: 10.2147/RRB.S65700

Hirsch, J. A., Schubert, C., Gurevich, V. V., and Sigler, P. B. (1999). The 2.8 A crystal structure of visual arrestin: a model for arrestin's regulation. Cell. 97, 257-269. doi: 10.1016/S0092-8674(00)80735-7

Hollyfield, J. G., Besharse, J. C., and Rayborn, M. E. (1977). Turnover of rod photoreceptor outer segments. I. Membrane addition and loss in relationship to temperature. J. Cell Biol. 75, 490-506. doi: 10.1083/jcb.75.2.490

Holopainen, J. M., Cheng, C. L., Molday, L. L., Johal, G., Coleman, J., Dyka, F., et al. (2010). Interaction and localization of the retinitis pigmentosa protein RP2 and NSF in retinal photoreceptor cells. Biochemistry 49, 7439-7447. doi: 10.1021/bi1005249

Hong, D.-H., Yue, G., Adamian, M., and Li, T. (2001). Retinitis Pigmentosa GTPase regulator (RPGR)-interacting protein is stably associated with the photoreceptor ciliary axoneme and anchors rpgr to the connecting cilium. J. Biol. Chem. 276, 12091-12099. doi: 10.1074/jbc.M009351200

Hsu, Y., Garrison, J. E., Kim, G., Schmitz, A. R., Searby, C. C., Zhang, Q., et al. (2017). BBSome function is required for both the morphogenesis and maintenance of the photoreceptor outer segment. PLoS Genet. 13:e1007057. doi: 10.1371/journal.pgen.1007057

Hu, Q., Milenkovic, L., Jin, H., Scott, M. P., Nachury, M. V., Spiliotis, E. T., et al. (2010). A septin diffusion barrier at the base of the primary cilium maintains ciliary membrane protein distribution. Science 329, 436-439. doi: 10.1126/science.1191054

Huang, S. P., Brown, B. M., and Craft, C. M. (2010). Visual Arrestin 1 acts as a modulator for $\mathrm{N}$-ethylmaleimide-sensitive factor in the photoreceptor synapse. J Neurosci. 30, 9381-9391. doi: 10.1523/JNEUROSCI.1207-10.2010

Hubbell, W. L., Altenbach, C., Hubbell, C. M., and Khorana, H. G. (2003). "Rhodopsin structure, dynamics, and activation: a perspective from crystallography, site-directed spin labeling, sulfhydryl reactivity, and disulfide cross-linking," in Advances in Protein Chemistry, Vol. 63, eds F. M. Richars, D. S. Eisenberg, and J. Kuriyan (San Deigo, CA: Academic Press), 243-290. doi: 10.1016/S0065-3233(03)63010-X

Humrich, J., Bermel, C., Grubel, T., Quitterer, U., and Lohse, M. J. (2003). Regulation of phosducin-like protein by casein kinase 2 and N-terminal splicing. J. Biol. Chem. 278, 4474-4481. doi: 10.1074/jbc.M206347200

Ikeda, S., Shiva, N., Ikeda, A., Smith, R. S., Nusinowitz, S., Yan, G., et al. (2000). Retinal degeneration but not obesity is observed in null mutants of the tubbylike protein 1 gene. Hum Mol Genet. 9, 155-163. doi: 10.1093/hmg/9.2.155

Imamoto, Y., Tamura, C., Kamikubo, H., and Kataoka, M. (2003). Concentrationdependent tetramerization of bovine visual arrestin. Biophys J. 85, 1186-1195. doi: 10.1016/S0006-3495(03)74554-8

Imanishi, Y. (2019). Protein Sorting in Healthy and Diseased Photoreceptors. Annu. Rev. Vis. Sci. 5, 73-98. doi: 10.1146/annurev-vision-091718-014843

Inglese, J., Glickman, J. F., Lorenz, W., Caron, M. G., and Lefkowitz, R. J. (1992). Isoprenylation of a protein kinase. Requirement of farnesylation/alphacarboxyl methylation for full enzymatic activity of rhodopsin kinase. J. Biol. Chem. 267, 1422-1425. doi: 10.1016/S0021-9258(18)45960-1

Insinna, C., Humby, M., Sedmak, T., Wolfrum, U., and Besharse, J. C. (2009). Different roles for KIF17 and kinesin II in photoreceptor development and maintenance. Dev. Dyn. 238, 2211-2222. doi: 10.1002/dvdy.21956

Insinna, C., Pathak, N., Perkins, B., Drummond, I., and Besharse, J. C. (2008). The homodimeric kinesin, Kif17, is essential for vertebrate photoreceptor sensory outer segment development. Dev Biol. 316, 160-170. doi: 10.1016/j.ydbio.2008.01.025

Ismail, S. A., Chen, Y. X., Miertzschke, M., Vetter, I. R., Koerner, C., and Wittinghofer, A. (2012). Structural basis for Arl3-specific release of myristoylated ciliary cargo from UNC119. EMBO J. 31, 4085-4094. doi: $10.1038 /$ emboj.2012.257
Jacoby, M., Cox, J. J., Gayral, S., Hampshire, D. J., Ayub, M., Blockmans, M., et al. (2009). INPP5E mutations cause primary cilium signaling defects, ciliary instability and ciliopathies in human and mouse. Nat Gen. 41, 1027-1031. doi: $10.1038 /$ ng. 427

Janson, L. W., Ragsdale, K., and Luby-Phelps, K. (1996). Mechanism and size cutoff for steric exclusion from actin-rich cytoplasmic domains. Biophys J. 71, 1228-1234. doi: 10.1016/S0006-3495(96)79367-0

Jensen, V. L., Li, C., Bowie, R. V., Clarke, L., Mohan, S., Blacque, O. E., et al. (2015). Formation of the transition zone by Mks5/Rpgrip1L establishes a ciliary zone of exclusion (CIZE) that compartmentalises ciliary signalling proteins and controls PIP2 ciliary abundance. EMBO J. 34, 2537-2556. doi: $10.15252 / \mathrm{embj} .201488044$

Jiang, J., Promchan, K., Jiang, H., Awasthi, P., Marshall, H., Harned, A., et al. (2016). Depletion of BBS protein LZTFL1 affects growth and causes retinal degeneration in mice. J. Genet. Genomics. 43, 381-391. doi: 10.1016/j.jgg.2015.11.006

Jiang, L., Tam, B. M., Ying, G., Wu, S., Hauswirth, W. W., Frederick, J. M., et al. (2015a). Kinesin family 17 (osmotic avoidance abnormal-3) is dispensable for photoreceptor morphology and function. FASEB J. 29, 4866-4880. doi: 10.1096/fj.15-275677

Jiang, L., Wei, Y., Ronquillo, C. C., Marc, R. E., Yoder, B. K., Frederick, J. M., et al. (2015b). Heterotrimeric kinesin-2 (KIF3) mediates transition zone and axoneme formation of mouse photoreceptors. J. Biol. Chem. 290, 12765-12778. doi: 10.1074/jbc.M115.638437

Jimeno, D., Feiner, L., Lillo, C., Teofilo, K., Goldstein, L. S., Pierce, E. A., et al. (2006). Analysis of kinesin-2 function in photoreceptor cells using synchronous Cre-loxP knockout of Kif3a with RHO-Cre. Invest. Ophthalmol. Vis. Sci. 47, 5039-5046. doi: 10.1167/iovs.06-0032

Jordan, M. A., Diener, D. R., Stepanek, L., and Pigino, G. (2018). The cryo-EM structure of intraflagellar transport trains reveals how dynein is inactivated to ensure unidirectional anterograde movement in cilia. Nat. Cell Biol. 20, 1250-1255. doi: 10.1038/s41556-018-0213-1

Kandachar, V., Tam, B. M., Moritz, O. L., and Deretic, D. (2018). An interaction network between the SNARE VAMP7 and Rab GTPases within a ciliary membrane-targeting complex. J. Cell Sci. 131:jcs222034. doi: $10.1242 /$ jcs. 222034

Kaplan, M. W., Iwata, R. T., and Sears, R. C. (1987). Lengths of immunolabeled ciliary microtubules in frog photoreceptor outer segments. Exp. Eye Res. 44, 623-632. doi: 10.1016/S0014-4835(87)80134-3

Kawamura, S. (1993). Rhodopsin phosphorylation as a mechanism of cyclic GMP phosphodiesterase regulation by S-modulin. Nature 362, 855-857. doi: $10.1038 / 362855 \mathrm{a} 0$

Kawamura, S., Hisatomi, O., Kayada, S., Tokunaga, F., and Kuo, C. H. (1993). Recoverin has S-modulin activity in frog rods. J. Biol. Chem. 268, 14579-14582. doi: 10.1016/S0021-9258(18)82369-9

Keady, B. T., Le, Y. Z., and Pazour, G. J. (2011). IFT20 is required for opsin trafficking and photoreceptor outer segment development. Mol. Biol. Cell. 22, 921-930. doi: 10.1091/mbc.e10-09-0792

Kiesel, P., Viar, G. A., Tsoy, N., Maraspini, R., Gorilak, P., Varga, V., et al. (2020). The molecular structure of mammalian primary cilia revealed by cryoelectron tomography. Nat. Struct. Mol. Biol. 27, 1-10. doi: 10.1038/s41594-0200507-4

Kim, M., Hanson, S. M., Vishnivetskiy, S. A., Song, X., Cleghorn, W. M., Hubbell, W. L., et al. (2011). Robust self-association is a common feature of mammalian visual arrestin-1. Biochemistry 50, 2235-2242. doi: 10.1021/bi1018607

Klenchin, V. A., Calvert, P. D., and Bownds, M. D. (1995). Inhibition of rhodopsin kinase by recoverin. Further evidence for a negative feedback system in phototransduction. J. Biol. Chem. 270, 16147-16152. doi: $10.1074 /$ jbc.270.27.16147

Klink, B. U., Zent, E., Juneja, P., Kuhlee, A., Raunser, S., and Wittinghofer, A. (2017). A recombinant BBSome core complex and how it interacts with ciliary cargo. Elife 6:e27434. doi: 10.7554/eLife.27434

Kobayashi, A., Kubota, S., Mori, N., McLaren, M. J., and Inana, G. (2003). Photoreceptor synaptic protein HRG4 (UNC119) interacts with ARL2 via a putative conserved domain. FEBS Let. 534, 26-32. doi: 10.1016/S0014-5793(02)03766-3

Kobayashi, T., Ishida, Y., Hirano, T., Katoh, Y., and Nakayama, K. (2020). Cooperation of the IFT-A complex with the IFT-B complex is required 
for ciliary retrograde protein trafficking and GPCR import. Mol. Biol. Cell. 32:mbc. E20-08-0556. doi: 10.1091/mbc.E20-08-0556

Kolandaivelu, S., Huang, J., Hurley, J. B., and Ramamurthy, V. (2009). AIPL1, a protein associated with childhood blindness, interacts with alpha-subunit of rod phosphodiesterase (PDE6) and is essential for its proper assembly. J. Biol. Chem. 284, 30853-30861. doi: 10.1074/jbc.M109.036780

Kozminski, K. G., Johnson, K. A., Forscher, P., and Rosenbaum, J. L. (1993). A motility in the eukaryotic flagellum unrelated to flagellar beating. Proc. Natl. Acad. Sci. U.S.A. 90, 5519-5523. doi: 10.1073/pnas.90.12.5519

Krispel, C. M., Sokolov, M., Chen, Y. M., Song, H., Herrmann, R., Arshavsky, V. Y., et al. (2007). Phosducin regulates the expression of transducin betagamma subunits in rod photoreceptors and does not contribute to phototransduction adaptation. J. Gen. Physiol. 130, 303-312. doi: 10.1085/jgp.200709812

Krock, B. L., Mills-Henry, I., and Perkins, B. D. (2009). Retrograde intraflagellar transport by cytoplasmic dynein-2 is required for outer segment extension in vertebrate photoreceptors but not arrestin translocation. Invest. Ophthal. Vis. Sci. 50, 5463-5471. doi: 10.1167/iovs.09-3828

Krock, B. L., and Perkins, B. D. (2008). The intraflagellar transport protein IFT57 is required for cilia maintenance and regulates IFT-particle-kinesinII dissociation in vertebrate photoreceptors. J. Cell Sci. 121, 1907-1915. doi: $10.1242 /$ jcs.029397

Lai, R. K., Perez-Sala, D., Canada, F. J., and Rando, R. R. (1990). The gamma subunit of transducin is farnesylated. Proc. Natl. Acad. Sci. U.S.A. 87, 7673-7677. doi: 10.1073/pnas.87.19.7673

Lamb, T. D. (2013). Evolution of phototransduction, vertebrate photoreceptors and retina. Progress Retinal Eye Res. 36, 52-119. doi: 10.1016/j.preteyeres.2013.06.001

Lamb, T. D., Collin, S. P., and Pugh, E. N Jr. (2007). Evolution of the vertebrate eye: opsins, photoreceptors, retina and eye cup. Nat. Rev. Neurosci. 8, 960-976. doi: $10.1038 / \mathrm{nrn} 2283$

Lechtreck, K. F. (2015). IFT-cargo interactions and protein transport in cilia. Trends Biochem Sci. 40, 765-778. doi: 10.1016/j.tibs.2015.09.003

Lechtreck, K. F., Brown, J. M., Sampaio, J. L., Craft, J. M., Shevchenko, A., Evans, J. E., et al. (2013). Cycling of the signaling protein phospholipase D through cilia requires the BBSome only for the export phase. J. Cell Biol. 201, 249-261. doi: $10.1083 /$ jcb.201207139

Lee, R. H., Lieberman, B. S., and Lolley, R. N. (1987). A novel complex from bovine visual cells of a 33,000-dalton phosphoprotein with beta- and gammatransducin: purification and subunit structure. Biochemistry 26, 3983-3990. doi: 10.1021/bi00387a036

Lee, S., Tan, H. Y., Geneva, I. I., Kruglov, A., and Calvert, P. D. (2018a). Actin filaments partition primary cilia membranes into distinct fluid corrals. J Cell Biol. 217, 2831-2849. doi: 10.1083/jcb.201711104

Lee, S. H., Joo, K., Jung, E. J., Hong, H., Seo, J., and Kim, J. (2018b). Export of membrane proteins from the Golgi complex to the primary cilium requires the kinesin motor, KIFC1. Faseb J. 32, 957-968. doi: 10.1096/fj.201700563R

Lenoir, M., and Overduin, M. (2013). PtdIns(4)P signalling and recognition systems. Adv. Exp. Med. Biol. 991, 59-83. doi: 10.1007/978-94-007-6331-9_5

Li, C., Jensen, V. L., Park, K., Kennedy, J., Garcia-Gonzalo, F. R., Romani, M., et al. (2016). MKS5 and CEP290 dependent assembly pathway of the ciliary transition zone. PLoS Biol. 14:e1002416. doi: 10.1371/journal.pbio.1002416

Lin, Y. C., Niewiadomski, P., Lin, B., Nakamura, H., Phua, S. C., Jiao, J., et al. (2013). Chemically inducible diffusion trap at cilia reveals molecular sieve-like barrier. Nat. Chem. Biol. 9, 437-443. doi: 10.1038/nchembio.1252

Liu, P., and Lechtreck, K. F. (2018). The Bardet-Biedl syndrome protein complex is an adapter expanding the cargo range of intraflagellar transport trains for ciliary export. Proc. Natl. Acad. Sci. U.S.A. 115:E934-E943. doi: $10.1073 /$ pnas. 1713226115

Liu, Q., Tan, G., Levenkova, N., Li, T., Pugh, E. NJr., Rux, J. J., et al. (2007). The proteome of the mouse photoreceptor sensory cilium complex. Mol. Cell Proteomics. 6, 1299-1317. doi: 10.1074/mcp.M700054-MCP200

Liu, Y., and Bankaitis, V. A. (2010). Phosphoinositide phosphatases in cell biology and disease. Progress Lipid Res. 49, 201-217. doi: 10.1016/j.plipres.2009.12.001

Lodowski, K. H., Lee, R., Ropelewski, P., Nemet, I., Tian, G., and Imanishi, Y. (2013). Signals governing the trafficking and mistrafficking of a ciliary GPCR, rhodopsin. J Neurosci. 33, 13621-13638. doi: 10.1523/JNEUROSCI.1520-13.2013
Loew, A., Ho, Y. K., Blundell, T., and Bax, B. (1998). Phosducin induces a structural change in transducin beta gamma. Structure 6, 1007-1019. doi: 10.1016/S0969-2126(98)00102-6

Luby-Phelps, K., Fogerty, J., Baker, S. A., Pazour, G. J., and Besharse, J. C. (2008). Spatial distribution of intraflagellar transport proteins in vertebrate photoreceptors. Vision Res. 48, 413-423. doi: 10.1016/j.visres.2007.08.022

Luby-Phelps, K., Taylor, D. L., and Lanni, F. (1986). Probing the structure of cytoplasm. J Cell Biol. 102, 2015-2022. doi: 10.1083/jcb.102.6.2015

Luo, N., West, C. C., Murga-Zamalloa, C. A., Sun, L., Anderson, R. M., Wells, C. D., et al. (2012). OCRL localizes to the primary cilium: a new role for cilia in Lowe syndrome. Hum. Mol. Genet. 21, 3333-3344. doi: 10.1093/hmg/dds163

Makino, C. L., Dodd, R. L., Chen, J., Burns, M. E., Roca, A., Simon, M. I., et al. (2004). Recoverin regulates light-dependent phosphodiesterase activity in retinal rods. J. Gen. Physiol. 123, 729-741. doi: 10.1085/jgp.200308994

Marszalek, J. R., Liu, X., Roberts, E. A., Chui, D., Marth, J. D., Williams, D. S., et al. (2000). Genetic evidence for selective transport of opsin and arrestin by kinesin-II in mammalian photoreceptors. Cell 102, 175-187. doi: 10.1016/S0092-8674(00)00023-4

Maza, N. A., Schiesser, W. E., and Calvert, P. D. (2019). An intrinsic compartmentalization code for peripheral membrane proteins in photoreceptor neurons. J. Cell Biol. 218, 3753-3772. doi: 10.1083/jcb.201906024

Mazelova, J., Astuto-Gribble, L., Inoue, H., Tam, B. M., Schonteich, E., Prekeris, R., et al. (2009). Ciliary targeting motif $\mathrm{VxPx}$ directs assembly of a trafficking module through Arf4. EMBO J. 28, 183-192. doi: 10.1038/emboj. 2008.267

Mendez, A., Lem, J., Simon, M., and Chen, J. (2003). Lightdependent translocation of arrestin in the absence of rhodopsin phosphorylation and transducin signaling. J. Neurosci. 23, 3124-3129. doi: 10.1523/JNEUROSCI.23-08-03124.2003

Milenkovic, L., Weiss, L. E., Yoon, J., Roth, T. L., Su, Y. S., Sahl, S. J., et al. (2015). Single-molecule imaging of Hedgehog pathway protein Smoothened in primary cilia reveals binding events regulated by Patched1. Proc. Natl. Acad. Sci. U.S.A. 112, 8320-8325. doi: 10.1073/pnas.1510094112

Minton, A. P. (1992). Confinement as a determinant of macromolecular structure and reactivity. Biophys J. 63, 1090-1100. doi: 10.1016/S0006-3495(92)81663-6

Minton, A. P. (1997). Influence of excluded volume upon macromolecular structure and associations in 'crowded' media. Curr. Opin. Biotech. 8, 65-69. doi: 10.1016/S0958-1669(97)80159-0

Molday, R. S., and Goldberg, A. F. X. (2017). Peripherin diverts ciliary ectosome release to photoreceptor disc morphogenesis. J. Cell Biol. 216, 1227-1229. doi: $10.1083 /$ jcb.201703020

Molday, R. S., and Molday, L. L. (1987). Differences in the protein composition of bovine retinal rod outer segment disk and plasma membranes isolated by a ricin-gold-dextran density perturbation method. J. Cell Biol. 105, 2589-2601. doi: $10.1083 /$ jcb.105.6.2589

Molday, R. S., and Molday, L. L. (1998). Molecular properties of the cGMP-gated channel of rod photoreceptors. Vision Res. 38, 1315-1323. doi: 10.1016/S0042-6989(97)00409-4

Moritz, O. L., Tam, B. M., Hurd, L. L., Peranen, J., Deretic, D., and Papermaster, D. S. (2001). Mutant rab8 Impairs docking and fusion of rhodopsin-bearing postGolgi membranes and causes cell death of transgenic Xenopus rods. Mol. Biol. Cell. 12, 2341-2351. doi: 10.1091/mbc.12.8.2341

Moye, A. R., Singh, R., Kimler, V. A., Dilan, T. L., Munezero, D., Saravanan, T., et al. (2018). ARL2BP, a protein linked to retinitis pigmentosa, is needed for normal photoreceptor cilia doublets and outer segment structure. Mol. Biol. Cell. 29, 1590-1598. doi: 10.1091/mbc.E18-01-0040

Mukhopadhyay, S., Wen, X., Chih, B., Nelson, C. D., Lane, W. S., Scales, S. J., et al. (2010). TULP3 bridges the IFT-A complex and membrane phosphoinositides to promote trafficking of $\mathrm{G}$ protein-coupled receptors into primary cilia. Genes Dev. 24, 2180-2193. doi: 10.1101/gad.1966210

Murga-Zamalloa, C. A., Desai, N. J., Hildebrandt, F., and Khanna, H. (2010). Interaction of ciliary disease protein retinitis pigmentosa GTPase regulator with nephronophthisis-associated proteins in mammalian retinas. Mol. Vision 16, 1373-1381. Available online at: http://www.molvis.org/molvis/v16/a151

Murray, A. R., Fliesler, S. J., and Al-Ubaidi, M. R. (2009). Rhodopsin: the functional significance of asn-linked glycosylation and other post-translational modifications. Ophthal. Genet. 30, 109-120. doi: 10.1080/13816810902962405 
Nachury, M. V. (2018). The molecular machines that traffic signaling receptors into and out of cilia. Curr. Opin. Cell Biol. 51, 124-131. doi: 10.1016/j.ceb.2018.03.004

Nager, A. R., Goldstein, J. S., Herranz-Perez, V., Portran, D., Ye, F., GarciaVerdugo, J. M., et al. (2017). An actin network dispatches ciliary gpcrs into extracellular vesicles to modulate signaling. Cell 168, 252-263 e214. doi: 10.1016/j.cell.2016.11.036

Nair, K. S., Hanson, S. M., Kennedy, M. J., Hurley, J. B., Gurevich, V. V., and Slepak, V. Z. (2004). Direct binding of visual arrestin to microtubules determines the differential subcellular localization of its splice variants in rod photoreceptors. J. Biol. Chem. 279, 41240-41248. doi: 10.1074/jbc.M406768200

Nair, K. S., Hanson, S. M., Mendez, A., Gurevich, E. V., Kennedy, M. J., Shestopalov, V. I., et al. (2005). Light-dependent redistribution of arrestin in vertebrate rods is an energy-independent process governed by protein-protein interactions. Neuron 46, 555-567. doi: 10.1016/j.neuron.2005.03.023

Najafi, M., Maza, N. A., and Calvert, P. D. (2012). Steric volume exclusion sets soluble protein concentrations in photoreceptor sensory cilia. Proc. Natl. Acad. Sci. U.S.A. 109, 203-208. doi: 10.1073/pnas.1115109109

Nathans, J. (1992). Rhodopsin: structure, function, and genetics. Biochemistry 31, 4923-4931. doi: 10.1021/bi00136a001

Nemet, I., Tian, G., and Imanishi, Y. (2014). Submembrane assembly and renewal of rod photoreceptor cGMP-gated channel: insight into the actindependent process of outer segment morphogenesis. J. Neurosci. 34, 8164-8174. doi: 10.1523/JNEUROSCI.1282-14.2014

Nickell, S., Park, P. S., Baumeister, W., and Palczewski, K. (2007). Threedimensional architecture of murine rod outer segments determined by cryoelectron tomography. J. Cell Biol. 177, 917-925. doi: 10.1083/jcb.2006 12010

Nilsson, S. E. (1964). Receptor cell outer segment development and ultrastructure of the disk membranes in the retina of the tadpole (Rana Pipiens). J. Ultrastruct. Res. 11, 581-602. doi: 10.1016/S0022-5320(64)80084-8

Nir, I., and Pease, D. C. (1973). Ultrastructural aspects of discs in rod outer segments. Exp. Eye Res. 16, 173-182. doi: 10.1016/0014-4835(73)90211-X

Nishimura, D. Y., Fath, M., Mullins, R. F., Searby, C., Andrews, M., Davis, R., et al. (2004). Bbs2-null mice have neurosensory deficits, a defect in social dominance, and retinopathy associated with mislocalization of rhodopsin. Proc. Natl. Acad. Sci. U.S.A. 101, 16588-16593. doi: 10.1073/pnas.0405496101

Norton, A. W., Hosier, S., Terew, J. M., Li, N., Dhingra, A., Vardi, N., et al. (2005). Evaluation of the $17-\mathrm{kDa}$ prenyl-binding protein as a regulatory protein for phototransduction in retinal photoreceptors. J. Biol. Chem. 280, 1248-1256. doi: 10.1074/jbc.M410475200

Nozaki, S., Katoh, Y., Kobayashi, T., and Nakayama, K. (2018). BBS1 is involved in retrograde trafficking of ciliary GPCRs in the context of the BBSome complex. PLoS ONE. 13:e0195005. doi: 10.1371/journal.pone.0195005

Ohlemiller, K. K., Hughes, R. M., Mosinger-Ogilvie, J., Speck, J. D., Grosof, D. H., and Silverman, M. S. (1995). Cochlear and retinal degeneration in the tubby mouse. Neuroreport 6, 845-849. doi: 10.1097/00001756-199504190-00005

Ohlemiller, K. K., Mosinger Ogilvie, J., Lett, J. M., Hughes, R. M., LaRegina, M. C., and Olson, L. M. (1998). The murine tub (rd5) mutation is not associated with a primary axonemal defect. Cell Tissue Res. 291, 489-495. doi: $10.1007 / \mathrm{s} 004410051018$

Orisme, W., Li, J., Goldmann, T., Bolch, S., Wolfrum, U., and Smith, W. C. (2010). Light-dependent translocation of arrestin in rod photoreceptors is signaled through a phospholipase C cascade and requires ATP. Cell. Signal. 22, 447-456. doi: 10.1016/j.cellsig.2009.10.016

Otsu, W., Hsu, Y. C., Chuang, J. Z., and Sung, C. H. (2019). The late endosomal pathway regulates the ciliary targeting of tetraspanin protein peripherin 2 . J. Neurosci. 39, 3376-3393. doi: 10.1523/JNEUROSCI.2811-18.2019

Papermaster, D. S., Schneider, B. G., DeFoe, D., and Besharse, J. C. (1986). Biosynthesis and vectorial transport of opsin on vesicles in retinal rod photoreceptors. J. Histochem. Cytochem. 34, 5-16. doi: 10.1177/34.1.29 34469

Pazour, G. J., Baker, S. A., Deane, J. A., Cole, D. G., Dickert, B. L., Rosenbaum, J. L., et al. (2002). The intraflagellar transport protein, IFT88, is essential for vertebrate photoreceptor assembly and maintenance. J. Cell Biol. 157, 103-114. doi: $10.1083 /$ jcb. 200107108

Pearring, J. N., Lieu, E. C., Winter, J. R., Baker, S. A., and Arshavsky, V. Y. (2014). R9AP targeting to rod outer segments is independent of rhodopsin and is guided by the SNARE homology domain. Mol. Biol. Cell. 25, 2644-2649. doi: 10.1091/mbc.e14-02-0747

Pearring, J. N., Salinas, R. Y., Baker, S. A., and Arshavsky, V. Y. (2013). Protein sorting, targeting and trafficking in photoreceptor cells. Progress Retinal And Eye Res. 36, 24-51. doi: 10.1016/j.preteyeres.2013.03.002

Pearring, J. N., San Agustin, J. T., Lobanova, E. S., Gabriel, C. J., Lieu, E. C., Monis, W. J., et al. (2017). Loss of Arf4 causes severe degeneration of the exocrine pancreas but not cystic kidney disease or retinal degeneration. PLoS Genet. 13:e1006740. doi: 10.1371/journal.pgen.1006740

Pearring, J. N., Spencer, W. J., Lieu, E. C., and Arshavsky, V. Y. (2015). Guanylate cyclase 1 relies on rhodopsin for intracellular stability and ciliary trafficking. eLife 4:e12058. doi: 10.7554/eLife.12058

Pearring, J. N., Willer, J. R., Martínez-Márquez, J. Y., Lieu, E. C., Salinas, R. Y., and Arshavsky, V. Y. (2020). The GARP Domain of the Rod CNG Channel's $\beta 1$ subunit contains distinct sites for outer segment targeting and connecting to the photoreceptor disc rim. bioRxiv [Preprint]. doi: 10.1101/2020.10.01.322859

Peet, J. A., Bragin, A., Calvert, P. D., Nikonov, S. S., Mani, S., Zhao, X., et al. (2004). Quantification of the cytoplasmic spaces of living cells with EGFP reveals arrestin-EGFP to be in disequilibrium in dark adapted rod photoreceptors. J. Cell Sci. 117, 3049-3059. doi: 10.1242/jcs.01167

Peters, K. R., Palade, G. E., Schneider, B. G., and Papermaster, D. S. (1983). Fine structure of a periciliary ridge complex of frog retinal rod cells revealed by ultrahigh resolution scanning electron microscopy. J. Cell Biol. 96, 265-276. doi: $10.1083 /$ jcb.96.1.265

Peterson, J. J., Orisme, W., Fellows, J., McDowell, J. H., Shelamer, C. L., Dugger, D. R., et al. (2005). A role for cytoskeletal elements in the light-driven translocation of proteins in rod photoreceptors. Invest. Ophthalmol. Vis. Sci. 46, 3988-3998. doi: $10.1167 /$ iovs.05-0567

Peterson, J. J., Tam, B. M., Moritz, O. L., Shelamer, C. L., Dugger, D. R., McDowell, J. H., et al. (2003). Arrestin migrates in photoreceptors in response to light: a study of arrestin localization using an arrestin-GFP fusion protein in transgenic frogs. Exp Eye Res. 76, 553-563. doi: 10.1016/S0014-4835(03)00032-0

Peterson, S. M., McGill, T. J., Puthussery, T., Stoddard, J., Renner, L., Lewis, A. D., et al. (2019). Bardet-Biedl Syndrome in rhesus macaques: a nonhuman primate model of retinitis pigmentosa. Exp. Eye Res. 189:107825. doi: 10.1016/j.exer.2019.107825

Phua, S. C., Chiba, S., Suzuki, M., Su, E., Roberson, E. C., Pusapati, G. V., et al. (2017). Dynamic remodeling of membrane composition drives cell cycle through primary cilia excision. Cell 168, 264-279 e215. doi: 10.1016/j.cell.2016.12.032

Pigino, G., Geimer, S., Lanzavecchia, S., Paccagnini, E., Cantele, F., Diener, D. R., et al. (2009). Electron-tomographic analysis of intraflagellar transport particle trains in situ. J Cell Biol. 187, 135-148. doi: 10.1083/jcb.200905103

Ploier, B., Caro, L. N., Morizumi, T., Pandey, K., Pearring, J. N., Goren, M. A., et al. (2016). Dimerization deficiency of enigmatic retinitis pigmentosa-linked rhodopsin mutants. Nat. Commun. 7:12832. doi: 10.1038/ncomms12832

Poetsch, A., Molday, L. L., and Molday, R. S. (2001). The cGMP-gated channel and related glutamic acid-rich proteins interact with peripherin-2 at the rim region of rod photoreceptor disc membranes. J. Biol. Chem. 276, 48009-48016. doi: 10.1074/jbc.M108941200

Potter, V. L., Robichaux, M. A., Moye, A. R., and Wensel, T. G. (2020). Superresolution microscopy reveals photoreceptor-specific subciliary location and function of Cep290. bioRxiv [Preprint]. doi: 10.1101/2020.10.28.3 57806

Pretorius, P. R., Baye, L. M., Nishimura, D. Y., Searby, C. C., Bugge, K., Yang, B., et al. (2010). Identification and functional analysis of the vision-specific BBS3 (ARL6) long isoform. PLoS Genet. 6:e1000884. doi: 10.1371/journal.pgen.1000884

Prevo, B., Scholey, J. M., and Peterman, E. J. (2017). Intraflagellar transport: mechanisms of motor action, cooperation, and cargo delivery. FEBS J. 284, 2905-2931. doi: 10.1111/febs. 14068

Pugh, E. N. Jr., and Lamb, T. D. (2000). "Phototransduction in vertebrate rods and cones: molecular mechanisms of amplification, recovery and light adaptation," in Hanbook of Biological Physics. Vol. 3, eds D. G. Stavenga, W. J. de Grip, and E. N. Pugh (Amsterdam: Elsevier Science B. V), 183-255. doi: 10.1016/S1383-8121(00)80008-1

Qureshi, B. M., Schmidt, A., Behrmann, E., Burger, J., Mielke, T., C., et al. (2018). Mechanistic insights into the role of prenyl-binding protein $\mathrm{PrBP} /$ delta 
in membrane dissociation of phosphodiesterase 6. Nat. Commun. 9:90. doi: 10.1038/s41467-017-02569-y

Rabouille, C., Hui, N., Hunte, F., Kieckbusch, R., Berger, E. G., Warren, G., et al. (1995). Mapping the distribution of Golgi enzymes involved in the construction of complex oligosaccharides. J. Cell Sci. 108 (Pt 4), 1617-1627.

Ramamurthy, V., Jolicoeur, C., Koutroumbas, D., Mühlhans, J., Le, Y. Z., Hauswirth, W. W., et al. (2014). Numb regulates the polarized delivery of cyclic nucleotide-gated ion channels in rod photoreceptor cilia. J. Neurosci. 34, 13976-13987. doi: 10.1523/JNEUROSCI.1938-14.2014

Ramamurthy, V., Roberts, M. F., van den Akker, Niemi, G., Reh, T. A., and Hurley, J. B. (2003). AIPL1, a protein implicated in Leber's congenital amaurosis, interacts with and aids in processing of farnesylated proteins. Proc. Natl. Acad. Sci. U.S.A. 100, 12630-12635. doi: 10.1073/pnas.21341 94100

Rao, K. N., Zhang, W., Li, L., Anand, M., and Khanna, H. (2016). Prenylated retinal ciliopathy protein RPGR interacts with PDE6 $\delta$ and regulates ciliary localization of Joubert syndrome-associated protein INPP5E. Hum. Mol. Genet. 25, 4533-4545. doi: 10.1093/hmg/ddw281

Reilly, M. L., and Benmerah, A. (2019). Ciliary kinesins beyond IFT: cilium length, disassembly, cargo transport and signalling. Biol. Cell. 111, 79-94. doi: $10.1111 /$ boc. 201800074

Reiter, J. F., Blacque, O. E., and Leroux, M. R. (2012). The base of the cilium: roles for transition fibres and the transition zone in ciliary formation, maintenance and compartmentalization. EMBO Rep. 13, 608-618. doi: 10.1038/embor.2012.73

Reiter, J. F., and Leroux, M. R. (2017). Genes and molecular pathways underpinning ciliopathies. Nat. Rev. Mol. Cell Biol. 18, 533-547. doi: $10.1038 / \mathrm{nrm} .2017 .60$

Ritter, L. M., Khattree, N., Tam, B., Moritz, O. L., Schmitz, F., and Goldberg, A. F. (2011). In situ visualization of protein interactions in sensory neurons: glutamic acid-rich proteins (GARPs) play differential roles for photoreceptor outer segment scaffolding. J. Neurosci. 31, 11231-11243. doi: 10.1523/JNEUROSCI.2875-11.2011

Robichaux, M. A., Potter, V. L., Zhang, Z., He, F., Liu, J., Schmid, M. F., et al. (2019). Defining the layers of a sensory cilium with STORM and cryoelectron nanoscopy. Proc. Natl. Acad. Sci. U.S.A. 116, 23562-23572. doi: $10.1073 /$ pnas. 1902003116

Roepman, R., Bernoud-Hubac, N., Schick, D. E., Maugeri, A., Berger, W., H.,Ropers, H., et al. (2000). The retinitis pigmentosa GTPase regulator (RPGR) interacts with novel transport-like proteins in the outer segments of rod photoreceptors. Hum. Mol. Gene. 9, 2095-2105. doi: 10.1093/hmg/9.14.2095

Roof, D., Adamian, M., Jacobs, D., and Hayes, A. (1991). Cytoskeletal specializations at the rod photoreceptor distal tip. J. Comp. Neurol. 305, 289-303. doi: 10.1002/cne.903050210

Rosenbaum, J. L., and Witman, G. B. (2002). Intraflagellar transport. Nat. Rev. Mol. Cell Biol. 3, 813-825. doi: 10.1038/nrm952

Roy, K., Jerman, S., Jozsef, L., McNamara, T., Onyekaba, G., Sun, Z., et al. (2017). Palmitoylation of the ciliary GTPase ARL13b is necessary for its stability and its role in cilia formation. J. Biol. Chem. 292, 17703-17717. doi: 10.1074/jbc.M117.792937

Sale, W. S., Besharse, J. C., and Piperno, G. (1988). Distribution of acetylated alphatubulin in retina and in vitro-assembled microtubules. Cell Motil. Cytoskeleton. 9, 243-253. doi: 10.1002/cm.970090306

Salinas, R. Y., Baker, S. A., Gospe, S. M. 3rd, and Arshavsky, V. Y. (2013). A single valine residue plays an essential role in peripherin/rds targeting to photoreceptor outer segments. PLoS ONE. 8:e54292. doi: 10.1371/journal.pone.0054292

Salinas, R. Y., Pearring, J. N., J.-,Ding, D., Spencer, W. J., Hao, Y., and Arshavsky, V. Y. (2017). Photoreceptor discs form through peripherindependent suppression of ciliary ectosome release. J. Cell Biol. 216, 1489-1499. doi: $10.1083 /$ jcb. 201608081

Santagata, S., Boggon, T. J., Baird, C. L., Gomez, C. A., Zhao, J., Shan, W. S., et al. (2001). G-protein signaling through tubby proteins. Science 292, 2041-2050. doi: $10.1126 /$ science. 1061233

Scholey, J. M. (2013). Kinesin-2: a family of heterotrimeric and homodimeric motors with diverse intracellular transport functions. Ann. Rev. Cell Dev. Biol. 29, 443-469. doi: 10.1146/annurev-cellbio-101512-122335
Schubert, C., Hirsch, J. A., Gurevich, V. V., Engelman, D. M., Sigler, P. B., and Fleming, K. G. (1999). Visual arrestin activity may be regulated by selfassociation. J. Biol. Chem. 274, 21186-21190. doi: 10.1074/jbc.274.30.21186

Sedmak, T., and Wolfrum, U. (2011). Intraflagellar transport proteins in ciliogenesis of photoreceptor cells. Biol. Cell. 103, 449-466. doi: 10.1042/BC20110034

Shi, X., Garcia, G. 3rd, J. C., Van De Weghe, McGorty, R., Pazour, G. J., Doherty, D., Huang, B., et al. (2017). Super-resolution microscopy reveals that disruption of ciliary transition-zone architecture causes Joubert syndrome. Nat. Cell Biol. 19, 1178-1188. doi: 10.1038/ncb3599

Shilton, B. H., McDowell, J. H., Smith, W. C., and Hargrave, P. A. (2002). The solution structure and activation of visual arrestin studied by small-angle X-ray scattering. Eur. J. Biochem. 269, 3801-3809. doi: 10.1046/j.1432-1033.2002.03071.x

Shinde, S. R., Nager, A. R., and Nachury, M. V. (2020). Ubiquitin chains earmark GPCRs for BBSome-mediated removal from cilia. J. Cell Biol. 219:e202003020. doi: $10.1083 /$ jcb. 202003020

Simons, D. L., Boye, S. L., Hauswirth, W. W., and Wu, S. M. (2011). Gene therapy prevents photoreceptor death and preserves retinal function in a BardetBiedl syndrome mouse model. Proc. Natl. Acad. Sci. U.S.A. 108, 6276-6281. doi: $10.1073 /$ pnas. 1019222108

Sinha, S., Majumder, A., Belcastro, M., Sokolov, M., and Artemyev, N. O. (2013). Expression and subcellular distribution of UNC119a, a protein partner of transducin alpha subunit in rod photoreceptors. Cell. Signal. 25, 341-348. doi: 10.1016/j.cellsig.2012.10.005

Smith, W. C., Bolch, S., Dugger, D. R., Li, J., Esquenazi, I., Arendt, A., et al. (2011). Interaction of arrestin with enolase1 in photoreceptors. Invest. Ophthalmol. Vis. Sci. 52, 1832-1840. doi: 10.1167/iovs.10-5724

Sohocki, M. M., Perrault, I., Leroy, B. P., Payne, A. M., Dharmaraj, S., Bhattacharya, S. S., et al. (2000). Prevalence of AIPL1 mutations in inherited retinal degenerative disease. Mol. Genet. Metab. 70, 142-150. doi: 10.1006/mgme.2000.3001

Sokolov, M., Strissel, K. J., Leskov, I. B., Michaud, N. A., Govardovskii, V. I., and Arshavsky, V. Y. (2004). Phosducin facilitates light-driven transducin translocation in rod photoreceptors. Evidence from the phosducin knockout mouse. J. Biol. Chem. 279, 19149-19156. doi: 10.1074/jbc.M311058200

Sokolov, M., Yadav, R. P., Brooks, C., and Artemyev, N. O. (2019). Chaperones and retinal disorders. Adv. Protein. Chem. Struct. Biol. 114, 85-117. doi: 10.1016/bs.apcsb.2018.09.001

Song, X., Vishnivetskiy, S. A., Seo, J., Chen, J., Gurevich, E. V., and Gurevich, V. V. (2011). Arrestin-1 expression level in rods: balancing functional performance and photoreceptor health. Neuroscience 174, 37-49. doi: 10.1016/j.neuroscience.2010.11.009

Spencer, W. J., Lewis, T. R., Pearring, J. N., and Arshavsky, V. Y. (2020). Photoreceptor discs: built like ectosomes. Trends Cell Biol. 30, 904-915. doi: $10.1016 /$ j.tcb.2020.08.005

Spencer, W. J., Lewis, T. R., Phan, S., Cady, M. A., Serebrovskaya, E. O., Schneider, N. F., et al. (2019). Photoreceptor disc membranes are formed through an Arp2/3-dependent lamellipodium-like mechanism. Proc. Natl. Acad. Sci. U.S.A. 116, 27043-27052. doi: 10.1073/pnas.1913518117

Spencer, W. J., Pearring, J. N., Salinas, R. Y., Loiselle, D. R., Skiba, N. P., and Arshavsky, V. Y. (2016). Progressive rod-cone degeneration (PRCD) Protein Requires N-Terminal S-acylation and rhodopsin binding for photoreceptor outer segment localization and maintaining intracellular stability. Biochemistry 55, 5028-5037. doi: 10.1021/acs.biochem.6b00489

Steinberg, R. H., Fisher, S. K., and Anderson, D. H. (1980). Disc morphogenesis in vertebrate photoreceptors. J. Comp. Neurol. 190, 501-508. doi: 10.1002/cne.901900307

Steinberg, R. H., and Wood, I. (1975). Clefts and microtubules of photoreceptor outer segments in the retina of the domestic cat. J. Ultrastruct Res. 51, 307-403. doi: 10.1016/S0022-5320(75)80102-X

Stepanek, L., and Pigino, G. (2016). Microtubule doublets are doubletrack railways for intraflagellar transport trains. Science 352, 721-724. doi: 10.1126/science.aaf4594

Stiles, W. S., and Crawford, B. H. (1933). The luminous efficiency of rays entering the eye pupil at different points. Proc. R. Soc; London. 112, 428-450. doi: $10.1098 / \mathrm{rspb} .1933 .0020$ 
Strissel, K. J., Lishko, P. V., Trieu, L. H., Kennedy, M. J., Hurley, J. B., and Arshavsky, V. Y. (2005). Recoverin undergoes light-dependent intracellular translocation in rod photoreceptors. J. Biol. Chem. 280, 29250-29255. doi: 10.1074/jbc.M501789200

Strissel, K. J., Sokolov, M., Trieu, L. H., and Arshavsky, V. Y. (2006). Arrestin translocation is induced at a critical threshold of visual signaling and is superstoichiometric to bleached rhodopsin. J. Neurosci. 26, 1146-1153. doi: 10.1523/JNEUROSCI.4289-05.2006

Sun, S., Fisher, R. L., Bowser, S. S., Pentecost, B. T., and Sui, H. (2019). Threedimensional architecture of epithelial primary cilia. Proc. Natl. Acad. Sci. U.S.A. 116, 9370-9379. doi: 10.1073/pnas.1821064116

Swiderski, R. E., Nishimura, D. Y., Mullins, R. F., Olvera, M. A., Ross, J. L., Huang, J., et al. (2007). Gene expression analysis of photoreceptor cell loss in bbs4knockout mice reveals an early stress gene response and photoreceptor cell damage. Invest. Ophthal. Vis. Sci. 48, 3329-3340. doi: 10.1167/iovs.06-1477

Takei, R., Katoh, Y., and Nakayama, K. (2018). Robust interaction of IFT70 with IFT52-IFT88 in the IFT-B complex is required for ciliogenesis. Biol. Open. 7:bio033241. doi: 10.1242/bio.033241

Tam, B. M., Moritz, O. L., and Papermaster, D. S. (2004). The C terminus of peripherin/rds participates in rod outer segment targeting and alignment of disk incisures. Mol. Biol. Cell. 15, 2027-2037. doi: 10.1091/mbc.e03-09-0650

Tanaka, T., Ames, J. B., Harvey, T. S., Stryer, L., and Ikura, M. (1995). Sequestration of the membrane-targeting myristoyl group of recoverin in the calcium-free state. Nature 376, 444-447. doi: 10.1038/376444a0

Taschner, M., Kotsis, F., Braeuer, P., Kuehn, E. W., and Lorentzen, E. (2014). Crystal structures of IFT70/52 and IFT52/46 provide insight into intraflagellar transport B core complex assembly. J. Cell Biol. 207, 269-282. doi: $10.1083 /$ jcb. 201408002

Taschner, M., Lorentzen, A., Mourao, A., Collins, T., Freke, G. M., Moulding, D., et al. (2018). Crystal structure of intraflagellar transport protein 80 reveals a homo-dimer required for ciliogenesis. Elife 7:e33067. doi: 10.7554/eLife.33067

Tian, G., Ropelewski, P., Nemet, I., Lee, R., Lodowski, K. H., and Imanishi, Y. (2014). An unconventional secretory pathway mediates the cilia targeting of peripherin/rds. J. Neurosci. 34, 992-1006. doi: 10.1523/JNEUROSCI.3437-13.2014

Trivedi, D., Colin, E., Louie, C. M., and Williams, D. S. (2012). Livecell imaging evidence for the ciliary transport of rod photoreceptor opsin by heterotrimeric kinesin-2. J. Neurosci. 32, 10587-10593. doi: 10.1523/JNEUROSCI.0015-12.2012

Trivedi, D., and Williams, D. S. (2010). Ciliary transport of opsin. Adv. Exp. Med. Biol. 664, 185-191. doi: 10.1007/978-1-4419-1399-9_21

Tsukamoto, Y. (1987). The number, depth and elongation of disc incisures in the retinal rod of Rana catesbeiana. Exp. Eye Res. 45, 105-116. doi: 10.1016/S0014-4835(87)80082-9

Vannuccini, E., Paccagnini, E., Cantele, F., Gentile, M., Dini, D., Fino, F., et al. (2016). Two classes of short intraflagellar transport train with different 3D structures are present in Chlamydomonas flagella. J. Cell Sci. 129, 2064-2074. doi: $10.1242 /$ jcs. 183244

Veltel, S., Kravchenko, A., Ismail, S., and Wittinghofer, A. (2008). Specificity of Arl2/Arl3 signaling is mediated by a ternary Arl3-effector-GAP complex. FEBS Lett. 582, 2501-2507. doi: 10.1016/j.febslet.2008.05.053

Volland, S., Hughes, L. C., Kong, C., Burgess, B. L., Linberg, K. A., Luna, G., et al. (2015). Three-dimensional organization of nascent rod outer segment disk membranes. Proc. Natl. Acad. Sci. U.S.A. 112, 14870-14875. doi: $10.1073 /$ pnas.1516309112

Wang, J., and Deretic, D. (2014). Molecular complexes that direct rhodopsin transport to primary cilia. Prog. Retin Eye Res. 38, 1-19. doi: 10.1016/j.preteyeres.2013.08.004

Wang, J., and Deretic, D. (2015). The Arf and Rab11 effector FIP3 acts synergistically with ASAP1 to direct Rabin8 in ciliary receptor targeting. J. Cell Sci. 128, 1375-1385. doi: 10.1242/jcs. 162925

Wang, J., Fresquez, T., Kandachar, V., and Deretic, D. (2017). The Arf GEF GBF1 and Arf4 synergize with the sensory receptor cargo, rhodopsin, to regulate ciliary membrane trafficking. J. Cell Sci. 130, 3975-3987. doi: $10.1242 /$ jcs. 205492

Wang, J., Morita, Y., Mazelova, J., and Deretic, D. (2012). The Arf GAP ASAP1 provides a platform to regulate Arf4- and Rab11-Rab8-mediated ciliary receptor targeting. EMBO J. 31, 4057-4071. doi: 10.1038/emboj.2012.253
Webb, S., Mukhopadhyay, A. G., and Roberts, A. J. (2020). Intraflagellar transport trains and motors: insights from structure. Semin. Cell Dev. Biol. 107, 82-90. doi: 10.1016/j.semcdb.2020.05.021

Weitz, D., Ficek, N., Kremmer, E., Bauer, P. J., and Kaupp, U. B. (2002). Subunit stoichiometry of the CNG channel of rod photoreceptors. Neuron 36, 881-889. doi: 10.1016/S0896-6273(02)01098-X

Wensel, T. G. (2020). Phosphoinositides in Retinal Function and Disease. Cells. 9:866. doi: 10.3390/cells9040866

Whelan, J. P., and McGinnis, J. F. (1988). Light-dependent subcellular movement of photoreceptor proteins. J. Neurosci. Res. 20, 263-270. doi: 10.1002/jnr.490200216

Wheway, G., Parry, D. A., and Johnson, C. A. (2014). The role of primary cilia in the development and disease of the retina. Organogenesis 10, 69-85. doi: $10.4161 /$ org. 26710

Williams, C. L., Li, C., Kida, K., Inglis, P. N., Mohan, S., Semenec, L., et al. (2011). MKS and NPHP modules cooperate to establish basal body/transition zone membrane associations and ciliary gate function during ciliogenesis. J. Cell Biol. 192, 1023-1041. doi: 10.1083/jcb.201012116

Wingfield, J. L., Mengoni, I., Bomberger, H., Y.-,Jiang, Y., Walsh, J. D., Brown, J. M., et al. (2017). IFT trains in different stages of assembly queue at the ciliary base for consecutive release into the cilium. Elife 6:e26609. doi: 10.7554/eLife.26609

Wingfield, J. L. K., Lechtreck, F., and Lorentzen, E. (2018). Trafficking of ciliary membrane proteins by the intraflagellar transport/BBSome machinery. Essays Biochem. 62, 753-763. doi: 10.1042/EBC20180030

Wolfrum, U., and Schmitt, A. (2000). Rhodopsin transport in the membrane of the connecting cilium of mammalian photoreceptor cells. Cell Motility Cytoskeleton. 46, 95-107. doi: 10.1002/1097-0169(200006)46:2<95::AID-CM2>3.0.CO;2-Q

Wong-Riley, M. T. T. (2010). Energy metabolism of the visual system. Eye Brain. 2, 99-116. doi: 10.2147/EB.S9078

Wright, K. J., Baye, L. M., Olivier-Mason, A., Mukhopadhyay, S., Sang, L. Kwong, M., et al. (2011). An ARL3-UNC119-RP2 GTPase cycle targets myristoylated NPHP3 to the primary cilium. Genes Dev. 25, 2347-2360. doi: $10.1101 / \mathrm{gad} .173443 .111$

Wright, Z. C., Loskutov, Y., Murphy, D., Stoilov, P., Pugacheva, E., A., et al. (2018). ADP-Ribosylation Factor-Like 2 (ARL2) regulates cilia stability and development of outer segments in rod photoreceptor neurons. Sci. Rep. 8:16967. doi: 10.1038/s41598-018-35395-3

Wright, Z. C., Singh, R. K., Alpino, R., Goldberg, A. F., Sokolov, M., and Ramamurthy, V. (2016). ARL3 regulates trafficking of prenylated phototransduction proteins to the rod outer segment. Hum. Mol. Genet. 25, 2031-2044. doi: 10.1093/hmg/ddw077

Xi, Q., Pauer, G. J., Ball, S. L., Rayborn, M., Hollyfield, J. G., Peachey, N. S., et al. (2007). Interaction between the photoreceptor-specific tubby-like protein 1 and the neuronal-specific GTPase dynamin-1. Invest. Ophthal. Vis. Sci. 48, 2837-2844. doi: 10.1167/iovs.06-0059

Xi, Q., Pauer, G. J., Marmorstein, A. D., Crabb, J. W., and Hagstrom, S. A. (2005). Tubby-like protein 1 (TULP1) interacts with F-actin in photoreceptor cells. Invest. Ophthal. Vis. Sci.. 46, 4754-4761. doi: 10.1167/iovs. 05-0693

Yadav, R. P., Boyd, K., Yu, L., and Artemyev, N. O. (2019). Interaction of the tetratricopeptide repeat domain of aryl hydrocarbon receptor-interacting protein-like 1 with the regulatory $\mathrm{P} \gamma$ subunit of phosphodiesterase 6. J. Biol. Chem. 294, 15795-15807. doi: 10.1074/jbc.RA119.010666

Yang, S., Bahl, K., H.-,Chou, T., Woodsmith, J., Stelzl, U., Walz, T., et al. (2020). Near-atomic structures of the BBSome reveal the basis for BBSome activation and binding to GPCR cargoes. Elife 9:e55954. doi: 10.7554/eLife. 55954

Yang, T. T., Chong, W. M., W.-,Wang, J., Mazo, G., Tanos, B., Chen, Z., et al. (2018). Super-resolution architecture of mammalian centriole distal appendages reveals distinct blade and matrix functional components. Nat. Commun. 9, 1-11. doi: 10.1038/s41467-018-04469-1

Yang, T. T., Su, J., Wang, W. J., Craige, B., Witman, G. B., Tsou, M. F., et al. (2015). Superresolution pattern recognition reveals the architectural map of the ciliary transition zone. Sci. Rep. 5:14096. doi: 10.1038/srep14096

Yang, T. T. M.,Tran, N. T., Chong, W. M., Huang, C. E., and Liao, J. C. (2019). Single-particle tracking localization microscopy reveals nonaxonemal 
dynamics of intraflagellar transport proteins at the base of mammalian primary cilia. Mol. Biol. Cell. 30, 828-837. doi: 10.1091/mbc.E18-10-0654

Yau, K. W., Matthews, G., and Baylor, D. A. (1979). Thermal activation of the visual transduction mechanism in retinal rods. Nature 279, 806-807. doi: 10.1038/279806a0

Ye, F., Breslow, D. K., Koslover, E. F., Spakowitz, A. J., Nelson, W. J., and Nachury, M. V. (2013). Single molecule imaging reveals a major role for diffusion in the exploration of ciliary space by signaling receptors. eLife 2:e00654. doi: $10.7554 /$ eLife.00654.025

Ye, F., Nager, A. R., and Nachury, M. V. (2018). BBSome trains remove activated GPCRs from cilia by enabling passage through the transition zone. J. Cell Biol. 217, 1847-1868. doi: 10.1083/jcb.201709041

Ying, G., Gerstner, C. D., Frederick, J. M., Boye, S. L., Hauswirth, W. W., and Baehr, W. (2016). Small GTPases Rab8a and Rab1la Are Dispensable for Rhodopsin Transport in Mouse Photoreceptors. PLoS ONE. 11:e0161236. doi: 10.1371 /journal.pone. 0161236

Young, R. W. (1967). The renewal of photoreceptor cell outer segments. J. Cell Biol. 33, 61-72. doi: $10.1083 /$ jcb.33.1.61

Young, R. W., and Bok, D. (1969). Participation of the retinal pigment epithelium in the rod outer segment renewal process. J. Cell Biol. 42, 392-403. doi: $10.1083 /$ jcb. 42.2 .392

Young, R. W., and Droz, B. (1968). The renewal of protein in retinal rods and cones. J. Cell Biol. 39, 169-184. doi: 10.1083/jcb.39.1.169

Yu, K., Liu, P., Venkatachalam, D., Hopkinson, B. M., and Lechtreck, K. F. (2020). The BBSome restricts entry of tagged carbonic anhydrase 6 into the cis-flagellum of Chlamydomonas reinhardtii. PLOS ONE. 15:e0240887. doi: 10.1371/journal.pone.0240887

Zhang, H., Constantine, R., Vorobiev, S., Chen, Y., Seetharaman, J., Huang, Y. J., et al. (2011a). UNC119 is required for G protein trafficking in sensory neurons. Nat. Neurosci. 14, 874-880. doi: 10.1038/nn.2835

Zhang, H., Huang, W., Zhang, H., Zhu, X., Craft, C. M., Baehr, W., et al. (2003). Light-dependent redistribution of visual arrestins and transducin subunits in mice with defective phototransduction. Mol. Vision 9, 231-237. Available online at: http://www.molvis.org/molvis/v9/a34/

Zhang, H., Li, S., Doan, T., Rieke, F., Detwiler, P. B., Frederick, J. M., et al. (2007). Deletion of PrBP/delta impedes transport of GRK1 and PDE6 catalytic subunits to photoreceptor outer segments. Proc. Natl. Acad. Sci. U.S.A. 104, 8857-8862. doi: 10.1073/pnas.0701681104

Zhang, H., Liu, X. H., Zhang, K., Chen, C. K., Frederick, J. M., Prestwich, G. D., et al. (2004). Photoreceptor cGMP phosphodiesterase delta subunit (PDEdelta) functions as a prenyl-binding protein. J. Biol. Chem. 279, 407-413. doi: 10.1074/jbc.M306559200

Zhang, P., Zawadzki, R. J., Goswami, M., Nguyen, P. T., Yarov-Yarovoy, V., Burns, M. E., et al. (2017). In vivo optophysiology reveals that G-protein activation triggers osmotic swelling and increased light scattering of rod photoreceptors. Proc. Natl. Acad. Sci. U.S.A. 114:E2937-E2946. doi: 10.1073/pnas.1620572114

Zhang, Q., Li, Y., Zhang, Y., Torres, V. E., Harris, P. C., Ling, K., et al. (2016a). GTP-binding of ARL-3 is activated by ARL-13 as a GEF and stabilized by UNC-119. Sci Rep. 6:24534. doi: 10.1038/srep24534
Zhang, Q., Nishimura, D., Seo, S., Vogel, T., Morgan, D. A., Searby, C., et al. (2011b). Bardet-Biedl syndrome 3 (Bbs3) knockout mouse model reveals common BBS-associated phenotypes and Bbs3 unique phenotypes. Proc. Natl. Acad. Sci. U.S.A. 108, 20678-20683. doi: 10.1073/pnas. 1113220108

Zhang, Q., Nishimura, D., Vogel, T., Shao, J., Swiderski, R., Yin, T., et al. (2013). BBS7 is required for BBSome formation and its absence in mice results in Bardet-Biedl syndrome phenotypes and selective abnormalities in membrane protein trafficking. J. Cell Sci. 126, 2372-2380. doi: 10.1242/jcs. 111740

Zhang, Q., Seo, S., Bugge, K., Stone, E. M., and Sheffield, V. C. (2012). BBS proteins interact genetically with the IFT pathway to influence SHHrelated phenotypes. Hum. Mol. Genet. 21, 1945-1953. doi: 10.1093/hmg/ dds004

Zhang, T., Cao, L. H., Kumar, S., Enemchukwu, N. O., Zhang, N., Lambert, A., et al. (2016b). Dimerization of visual pigments in vivo. Proc. Natl. Acad. Sci. U.S.A. 113, 9093-9098. doi: 10.1073/pnas.1609018113

Zheng, J., Trudeau, M. C., and Zagotta, W. N. (2002). Rod cyclic nucleotidegated channels have a stoichiometry of three CNGA1 subunits and one CNGB1 subunit. Neuron 36, 891-896. doi: 10.1016/S0896-6273(02)01099-1

Zhong, H., Molday, L. L., Molday, R. S., and Yau, K. W. (2002). The heteromeric cyclic nucleotide-gated channel adopts a 3A:1B stoichiometry. Nature 420, 193-198. doi: 10.1038/nature01201

Zhou, H. X., Rivas, G., and Minton, A. P. (2008). Macromolecular crowding and confinement: biochemical, biophysical, and potential physiological consequences. Annu. Rev. Biophys. 37, 375-397. doi: 10.1146/annurev.biophys.37.032807.125817

Zimmerman, S. B., and Minton, A. P. (1993). Macromolecular crowding: biochemical, biophysical, and physiological consequences. Annu. Re.v Biophys. Biomol. Struct. 22, 27-65. doi: 10.1146/annurev.bb.22.060193.000331

Zozulya, S., and Stryer, L. (1992). Calcium-myristoyl protein switch. Proc. Natl. Acad. Sci. U.S.A. 89, 11569-11573. doi: 10.1073/pnas.89.23.11569

Zulliger, R., Conley, S. M., Mwoyosvi, M. L., Stuck, M. W., Azadi, S., and Naash, M. I. (2015). SNAREs interact with retinal degeneration slow and rod outer segment membrane protein-1 during conventional and unconventional outer segment Targeting. PLoS ONE 10:e0138508. doi: 10.1371/journal.pone.0138508

Conflict of Interest: The authors declare that the research was conducted in the absence of any commercial or financial relationships that could be construed as a potential conflict of interest.

Copyright $\odot 2021$ Barnes, Malhotra and Calvert. This is an open-access article distributed under the terms of the Creative Commons Attribution License (CC BY). The use, distribution or reproduction in other forums is permitted, provided the original author(s) and the copyright owner(s) are credited and that the original publication in this journal is cited, in accordance with accepted academic practice. No use, distribution or reproduction is permitted which does not comply with these terms. 